Running head:

TERMINAL DECLINE IN WELL-BEING: CONSTELLATIONS OF CORRELATES

Terminal Decline in Well-Being:

The Role of Multi-Indicator Constellations of Physical Health and Psychosocial Correlates

Andreas M. Brandmaier ${ }^{1,2}$, Nilam Ram ${ }^{3,4}$, Gert G. Wagner ${ }^{1,3}$, \& Denis Gerstorf ${ }^{3,5}$

${ }^{1}$ Max Planck Institute for Human Development, Berlin, Germany

${ }^{2}$ Max Planck UCL Centre for Computational Psychiatry and Ageing Research, Berlin, Germany

${ }^{3}$ German Institute for Economic Research (DIW Berlin), Berlin, Germany

${ }^{4}$ Pennsylvania State University, University Park, US

${ }^{5}$ Humboldt University, Berlin, Germany

April 19, 2017

Address correspondence regarding this manuscript to: Andreas M. Brandmaier, Center for

Lifespan Psychology, Max Planck Institute for Human Development, Lentzeallee 94, 14195

Berlin, Germany; phone: +49-(0)30-82406-423; brandmaier@mpib-berlin.mpg.de.

Copyright (C) 2017 by the American Psychological Association. The official citation that should be used in referencing this material is: Brandmaier, A. M., Ram, N., Wagner, G. G., \& Gerstorf, D. (in press). Terminal Decline in Well-Being: The Role of Multi-Indicator Constellations of Physical Health and Psychosocial Correlates. Developmental Psychology. doi: http://dx.doi.org/10.1037/dev0000274. This article may not exactly replicate the authoritative document published in the APA journal. It is not the copy of record. 


\begin{abstract}
Well-being is often relatively stable across adulthood and old age, but typically exhibits pronounced deteriorations and vast individual differences in the terminal phase of life. However, the factors contributing to these differences are not well understood. Using up to 25-year annual longitudinal data obtained from 4,404 now-deceased participants of the nationwide German Socio-Economic Panel Study (SOEP; age at death: $M=73.2$ years; $S D=14.3$ years; $52 \%$ women), we explored the role of multi-indicator constellations of socio-demographic variables, physical health and burden factors, and psychosocial characteristics. Expanding earlier reports, Structural Equation Model Trees (SEM Trees) allowed us to identify profiles of variables that were associated with differences in the shape of late-life well-being trajectories. Physical health factors were found to play a major role for well-being decline, but in interaction with psychosocial characteristics such as social participation. To illustrate, for people with low social participation, disability emerged as the strongest correlate of differences in late-life well-being trajectories. However, for people with high social participation, whether or not an individual had spent considerable time in the hospital differentiated high vs. low and stable vs. declining latelife well-being. We corroborated these results with Variable Importance measures derived from a set of resampled SEM Trees (so-called SEM forests) that provide robust and comparative indicators of the total interactive effects of variables for differential late-life well-being. We discuss benefits and limitations of our approach and consider our findings in the context of other reports about protective factors against terminal decline in well-being.
\end{abstract}

Words: 249

Key words: Successful aging; life satisfaction; SEM forest; SEM tree; German Socio-Economic Panel Study 
Terminal Decline in Well-Being:

\section{The Role of Multi-Indicator Constellations of Physical Health and Psychosocial Correlates}

A variety of conceptual perspectives and a large body of empirical literature suggest that well-being remains largely stable throughout adulthood and old age (Brandstädter, 1999; Brickman \& Campbell, 1971; Carstensen, 2006; Diener, Suh, Lucas, \& Smith, 1999). The last years of life, in contrast, are often characterized by steep deteriorations in well-being, with substantial individual differences in how such terminal decline proceeds (for overview, see Gerstorf \& Ram, 2013). The factors that contribute to these individual differences in terminal decline of well-being have not yet been described in detail. In the present study, we make use of new data mining tools to identify constellations of socio-demographic, physical health and burden, and psychosocial characteristics that are associated with differences in terminal decline of well-being. Pearlin (1989) reminded us of the need to move away from a focus on single life events or strains as determinant of well-being and instead to examine constellations of acute and chronic stressors to fully understand their potentially interactive effects on well-being. For example, retirement may have a negative effect if associated with a loss of status but a positive effect if considered as an opportunity for self-fulfillment. In the same sense, we here present a data-analytic approach that specifically takes into account the interactive nature of a variety of potential life-events and characteristics. Specifically, we use Structural Equation Modeling Trees and Forests (Brandmaier, Prindle, McArdle, \& Lindenberger, in press; Brandmaier, von Oertzen, McArdle, \& Lindenberger, 2013) applied to 25-year annual longitudinal data obtained from 4,404 now-deceased participants of the nationwide German Socio-Economic Panel Study (SOEP; age at death: $M=73.2$ years; $S D=14.3$ years; $52 \%$ women) to identify correlates of terminal decline in well-being and their interactions.

\section{Terminal Decline in Well-Being and its Correlates}

A myriad of empirical reports converge in documenting that well-being takes a precipitous fall in the last years of life (Berg, Hassing, Thorvaldsson, \& Johansson, 2011; Burns, 
Mitchell, Shaw, \& Anstey, 2014; Carmel, Shrira, \& Shmotkin, 2013; Diehr, Williamson, Burke, \& Psaty, 2002; Mroczek \& Spiro, 2005; Palgi et al., 2014; Palgi et al., 2010; Schilling, Wahl, \& Oswald, 2013; Vogel, Schilling, Wahl, Beekman, \& Penninx, 2013; Windsor, Gerstorf, \& Luszcz, 2015). In the midst of such terminal decline, large individual differences exist, with some people experiencing steep decrements and others maintaining relatively high levels of well-being into late life. The factors contributing to these individual differences are not yet well understood. Theoretical work and empirical reports both suggest that socio-demographic, health and burden, and psychosocial characteristics to be relevant correlates. First, conceptual notions of reduced biological plasticity with advancing age (Baltes \& Smith, 2003) and life-long accumulation of socio-structural disadvantage (Mirowsky \& Ross, 2007; Moen, 1996) each suggest that the last years of life for very old adults, women, and lower educated population strata are each portended by increased risks for broad-based dysfunction. Consistent with these views, empirical evidence suggest that such socio-demographic characteristics are indeed associated with compromised well-being (Diehr et al., 2002; Gerstorf, Ram, Lindenberger, \& Smith, 2013).

Second, following the Strengths and Vulnerabilities Integration model (SAVI, Charles, 2010), chronic physical health conditions increasingly undermine the application of accumulated lifetime skills of emotion regulation. In line with this and other theoretical models (Lawton, 1983; Watson \& Pennebaker, 1989), proxy variables such as pathology, disability, and comorbidities have been linked with well-being, also late in life (Burns et al., 2014; Carmel et al., 2013; Infurna et al., 2014; Schilling et al., 2013). In a similar vein, a variety of major life events such as unemployment or bereavement are known to have long-lasting effects on wellbeing, among other reasons because such events are often associated with profound changes in daily routines (Lucas, 2007a).

Third, drawing from models of perceived control (Lachman, 2006), control perceptions presumably foster well-being by, for example, buffering the effects of stressors on physiological 
reactivity, helping to down-regulate negative emotions, and to mobilize social support when needed (see Gerstorf \& Ram, 2013). In line with these notions, our own work finds that perceived personal control is associated with higher levels of late-life well-being, less severe rates of terminal decline, and later onset of terminal decline (Gerstorf et al., 2014). Similarly, social participation and orientation presumably boost well-being in a number of ways, for example, because people pursue gratifying activities; because such activities promote feelings of competence, personal control, and self-esteem; or because a socially active lifestyle helps maintain physical and cognitive fitness (Herzog \& House, 1991; Lyubomirsky \& Layous, 2013). Again consistent with these conceptual considerations, Windsor and colleagues (2015) reported from the Australian Longitudinal Study of Aging that social engagement and satisfying relationships were associated with higher well-being at the end of life.

Relevant for the conceptual rationale of our study are several notes. Evidence for predictors of the between-person differences in terminal decline of well-being is generally sparse, with most of the correlates being associated with differences in level of well-being late in life, but not with differences in the rate of terminal decline. This is particularly true for the physical health factors, suggesting that poor physical health is just one set of relevant variables to consider. We argue that differential terminal decline is probably better discernible when we do not consider marginal associations, and rather consider a hybrid of idiographic and nomothetic analytical approaches that allow us to identify and examine constellations of risk and protective factors. In particular, we contend that the unique and shared effects of multiple variables, combined together, may represent the constellations of risk and protective factors that influence terminal decline in well-being. To illustrate, it would be intriguing to examine whether particular psychosocial characteristics are especially relevant in the context of severe health limitations. Berg and colleagues (2011) reported from the OCTO study that people who maintained high levels of perceived control late in life when suffering from severe physical health constraints maintained relatively high levels of life satisfaction. In a similar way, it is 
theoretically plausible that social resources boost perceived control in linear or non-linear ways that in turn help people maintain health and well-being into late-life (Antonucci, 2001; Cohen \& Wills, 1985). In our own work, it has not been possible, so far, to empirically test such notions in a single framework. In the current study, we move one step further by making use of a dataanalytic strategy that allows for more flexibility in how variables from different domains and different points in time are combined and analyzed simultaneously.

\section{Structural Equation Modeling Trees and Forests}

Structural equation model (SEM) Trees and Forests have recently been introduced into the literature as a methodological tool to structure and understand heterogeneity (Brandmaier et al., in press; Brandmaier et al., 2013; Brandmaier, von Oertzen, McArdle, \& Lindenberger, 2014). In brief, SEM Trees and SEM Forests are an instance of model-based recursive partitioning, a non-parametric statistical method that originates from the field of machine learning and data mining but can be traced back to early work on binary segmentation methods from five decades ago (Sonquist \& Morgan, 1964). In the same way that univariate decision trees provide a non-parametric alternative to regression models, SEM Trees can be regarded as a non-parametric alternative to expanding a SEM. Particularly, they offer a non-parametric way of adding predictors of sample heterogeneity (i.e., between-group differences) to an initial theorydriven, multivariate SEM. In the present paper, these methods are used to identify correlates of sample heterogeneity in SEM-based growth curves.

The decision tree approach allows us to target the complex, potentially interactive nature of a given set of hypothesized correlates in how they relate to individual differences in a given outcome (e.g., a growth curve). The non-parametric approach offered by trees enables us to model nonlinear interactions among the correlates (see Brandmaier et al., 2013), and also avoids making the often too strict assumption that effects are additive (e.g., as done in linear regression). Trees are particularly useful for data sets with a large number of potential correlates and interrelations that are expected to be complex and interactive. Essentially, trees operate by 
recursively splitting an initially heterogeneous sample into homogeneous subgroups. The method only maintains subgroups such that individuals within one group are highly similar and maximally different from other groups. In the present inquiry, individuals within one group are described by a SEM-based growth model that is maximally different from other groups' growth models. In decision tree approaches, only those subgroups that can be inferred from the set of candidate correlates are considered. The method resembles latent mixture models for modeling sub-populations in the overall population, with the difference that observed correlates are utilized to form and describe membership of individuals in subgroups. The recursive partitioning paradigm is increasingly applied in the social, behavioral, and life sciences. For example, in clinical decision making, decision trees have been applied to identify constellations of cognitive, biomarker and other variables as effective correlates for outcomes as diverse as treatment success of inpatient psychotherapy (Hannöver \& Kordy, 2005), alcohol or smoking behavior (Kitsantas, Kitsantas, \& Anagnostopoulou, 2008; Kitsantas, Moore, \& Sly, 2007), functional impairment (Lemsky, Smith, Malec, \& Ivnik, 1996), depression (Schmitz, Kugler, \& Rollnik, 2003), subjective memory impairment (Jessen et al., 2007), suicidal ideation in older people (Handley et al., 2014), and mortality hazards (Gruenewald, Seeman, Ryff, Karlamangla, \& Singer, 2006). Increasingly, these methods are also employed to support psychological theorybuilding, for example, to explore contextual features contributing to feelings of stress in later life (Scott, Jackson, \& Bergeman, 2011), to predict longitudinal attrition in surveys (McArdle, 2013), to explore differences in cross-sectional factor profiles and developmental latent growth curves of intelligence (Brandmaier et al., 2013), or to explore correlates of differential trajectories of cognitive functioning in old age (Brandmaier et al., 2014).

\section{Applying Structural Equation Modeling Trees and Forests to Study Terminal Decline (in}

\section{Well-Being)}

Research on well-being has so far primarily focused on bivariate associations when assessing how well-being relates to key correlates, such as social support, health, or socio- 
economic status (see Dolan, Peasgood, \& White, 2008). We have identified only two instances in which recursive partitioning has been used to describe how a multivariate set of correlates relate to well-being in adulthood and old age. First, Wallace, Bergeman, and Maxwell (2002) applied recursive partitioning analyses to cross-sectional data so as to investigate associations of protective factors (perceived control, social support coping, and physical health) with well-being in later life. Second, Gruenewald, Mroczek, Ryff, and Singer (2008) applied decision trees to cross-sectional data from the MIDUS study to explore social, psychological, behavioral, and socio-demographic correlates of negative affect and positive affect in adulthood and later life. Results revealed that correlates of well-being were in part specific to the valence category examined (some correlates, such as gender, were identified as significant predictors for positive affect, but not negative affect) as well as the age group considered (some correlates, such as physical health and marital status, in a tree predicting negative affect were identified as significant predictors among older adults, but not among middle-aged adults).

Using SEM Trees and SEM Forests, we extend these cross-sectional approaches by investigating potential correlates of individual differences in intraindividual patterns of change in well-being at the end of life. The decision tree approach allows us to target the complex, potentially interactive, nature of how these correlates relate to individual differences in terminal decline. We expect that not all relevant correlates operate in a simply additive fashion. For example, some may have compensatory effects (e.g., social support), whereas others have cumulative effects (e.g., perceived control and self-reported health). To illustrate, it is possible that people who suffer from disability but who manage to maintain their social orientation and remain socially active experience less pronounced well-being decrements relative to those with lowered social goals and/or reduced social participation. Or, as an illustration of a positive cumulative effects, beneficial effects of perceived control may be compounded by beneficial effects of increased self-reported health, (Wallace et al., 2002).

\section{The Present Study}


In the current study, we use SEM Trees and SEM Forests analyses of long-term longitudinal data from now-deceased participants in the SOEP to explore a large set of potential correlates of differences in terminal decline of well-being. We selected three sets of variables known to be associated with individual differences in mortality hazards and well-being (see Gerstorf \& Ram, 2013; Vaupel, 2010), including socio-demographics, health and burden factors, and psychosocial factors. We are building on and expanding two sets of earlier reports: Studies that used recursive partitioning to identify cross-sectional correlates of well-being in adulthood (Gruenewald et al., 2008; Wallace et al., 2002) and studies that used traditional growth models to identify correlates of terminal decline in well-being (Gerstorf et al., 2016). Specifically, we apply SEM Trees and SEM Forests to well-being data obtained in the last years of life so as to identify multi-way (nonlinear) constellations of socio-demographic, physical health and burden, and psychosocial factors associated with differences in terminal decline. These constellations encompass the complex combinations of conditions associated with severe forms of terminal decline in well-being and the constellations of conditions associated with less severe rates of decline.

\section{Method}

\section{Participants and Procedure}

The SOEP is a nationally representative annual panel study of private households that covers by now some 50,000 residents in Germany, including immigrants and resident foreigners (Headey, Muffels, \& Wagner, 2010). Data collection began in 1984. Participants were randomly selected from selected geographic locations in the former West and East Germany. Details of study materials and methods can be found in Wagner, Frick, and Schupp (2007). For the present analysis, we make use of the subsample of now deceased participants who provided data between 1984 and 2009. From these $N=4,886$ participants, we analyze data from the $n=4,404$ who completed at least a single assessment of well-being during the last ten years of their life. At the time of death, participants $(52.2 \%, n=2,297$ male) were on average 73.6 years old $(S D=$ 
$14.1, \min =18, \max =104)$, and had accumulated an average of 10.7 years of education $(S D=$ 2.1). For analysis of terminal decline, all available observations obtained in the last 10 years of life (between ages 17 and 102 years from birth) were realigned along a time-to-death time metric (spanning the 10 to 0 years before death). The median person provided six observations (range 1 to 11 ).

\section{Measures}

Well-being. Each year, participants were asked "Wie zufrieden sind Sie gegenwärtig, alles in allem, mit ihrem Leben?" (translated as "How satisfied are you currently with your life, all things considered?"). Responses were provided on an 11-point Likert scale ranging from 0 (totally unsatisfied) to 10 (completely satisfied) and are considered a measure of cognitiveevaluative components of well-being (as opposed to affective-emotional components; see Fujita \& Diener, 2005; Gerstorf et al., 2008; Gerstorf et al., 2010). For comparison with other studies, scores were rescaled to a $T$ metric $(M=50, S D=10)$ using the 2002 SOEP sample as the reference frame $(M=6.90, S D=1.81)$. On average, participants contributed $5.86(S D=3.38)$ longitudinal measurements, with $n=3,781(85.85 \%)$ participants contributing two or more data points. In the SEM Trees analysis framework, these repeated measures are placed within an SEM growth model that serves as the "outcome" of interest and is predicted by a variety of socio-demographic characteristics, physical health and burden factors, and psychosocial characteristics.

Socio-demographic characteristics. This category of correlates included age at death, sex, education, and religious participation. Interviewers assessed information about year of death and age at death either directly from relatives or neighbors or from the city registry. Death rates and ages of death in the SOEP study parallel official life tables and so are often used as a representative resource for mortality-related analyses in Germany (e.g., Brockmann \& Klein, 2004; Burkhauser, Giles, Lillard, \& Schwarze, 2005). Sex was noted as a binary variable (female =2). Participant's level of education was measured as total number of years of schooling (range 
$=7$ to 18). Participation in religion was measured with the item "Wie oft gehen Sie in die Kirche oder besuchen religiöse Veranstaltungen?" (translated as "How often do you attend church or other religious events?"), answered on a 1 (every week) to 4 (never) scale that was reverse coded so that higher scores indicate more religious participation.

Physical health and burden factors. Variables in this category encompassed documented risk factors for poor well-being and increased hazards of mortality (Vaupel, 2010), including physical health indicators (disability, hospitalization) and negative life events and burden (unemployment, divorce, and severe income loss as well as events experienced by close family members, including disability of the partner, unemployment of the partner, hospitalization of the partner, death of the partner, and death of the parents). All indicators were assessed annually or biennially and, before analysis, were converted into dichotomous timeinvariant variables indicating whether an event had happened at least once in the observational period. Disability and disability of partner were measured at each occasion as self-report of whether the participant or the participant's partner was "officially certified as having a reduced capacity to work or as severely handicapped" (see Lucas, 2007b). Disability indicators were thus based on self-reports, but referred to official certifications. Hospitalization and hospitalization of partner were designated whether the person had spent 56 nights or more in the hospital during the previous year. Unemployment and unemployment of partner indicated whether the person experienced a change from (fully or partly) "employed" to "registered unemployed". Income change indicates a change in individual gross labor income (before tax) of $-1,000$ or $-3,000$ $€ /$ month, without adjustments for household members or consumer prizes. Divorce, death of a partner, and death of a parent (only for target persons less than age 40) were noted by responses to the item "Hat sich an Ihrer familiären Situation im Jahr $X$ [z. Bsp. 2002] etwas verändert?" (translated as "Has your family situation changed since the beginning of year $X$ [e.g., 2002]?”), with specific designation for "wurde geschieden" ("got divorced”), "Ehepartner/Lebenspartner ist verstorben" (“spouse/partner has died”), Vater verstorben" ( "father died”), or "Mutter 
verstorben" (“mother died").

Psychosocial characteristics. This category of correlates included social participation, perceived control, and life goals. Social participation was measured using four items asking about frequency of involvement $(1=$ each week to $4=$ never $)$ in social and cultural activities, including going to events such as concerts, theaters, or lectures; active sport participation; honorary activity in clubs, organizations, or social service; and participation in citizen initiatives, parties, community politics. Responses from the last available assessment were reverse coded and averaged to obtain a social participation scale score where higher scores indicate more social participation (for details; see Infurna, Gerstorf, Ram, Schupp, \& Wagner, 2011). Perceived control was measured using 8 items assessing the degree to which individuals feel their life is under their control (e.g., "Ich kann ziemlich viel von dem, was in meinem Leben passiert, selbst bestimmen.", translated as "I determine most of what happens to me in life."), answered on a scale from 1 (applies completely) to 4 (does not apply). Responses from the last available assessment were reverse coded and averaged to obtain a perceived control scale score similar in conception to other measures of perceived control (see Lachman \& Weaver, 1998; Pearlin \& Schooler, 1978). Life goals were measured using a set of items that asked participants how much importance $(1=$ not at all important to $4=$ very important $)$ they attach to social goals (to help others, be involved in social and political activity), success goals (being able to buy things, importance of one own's job), and family goals (having a good marriage, having a good relationship with children; (for overview, see Headey, 2008). As with the other psychosocial variables, the last available assessment was used to index importance of goals in each of the three domains.

Sample Descriptives. In total, 20 variables are examined as candidate correlates of terminal decline in well-being. Descriptive statistics for the measures under study are given in Table 1. Correlations among the set of potential correlates and their correlations with terminal well-being are given in Table 2. 
Of note, there are no missing values for the demographic or health and burden variables, with the exception of religious activity that was missing for a quarter of the sample. In contrast, the amount of missing data in the psychosocial variables ranges from $11 \%$ (social participation) to $60 \%$ (control beliefs) because these variables were only assessed in specific years (e.g., perceived control only measured in 1994, 1995, and 1996). As a consequence, statistical power to detect effects is larger for the demographic and health and burden correlates than for the psychosocial correlates. As well, the frequency of occurrence for the negative life events is often low (e.g., about $1 \%$ for divorce), which may impede detection of correlations even if these are present.

SEM Model of Terminal Decline in Well-Being. Terminal decline in well-being was modeled in the SEM framework using standard latent growth curve models (LGCM; Duncan, Duncan, \& Strycker, 2013; Ferrer \& McArdle, 2003; Ferrer \& McArdle, 2010; Meredith \& Tisak, 1990; Ram \& Grimm, 2007). In univariate, unconditional LGCMs, the observed variables are repeated measures of the same variable. In contrast to the traditional factor model, the latent factors do not represent psychometric factors, but chronometric factors (e.g., Duncan et al., 2013; Preacher, 2008) capturing aspects of the change process over time. Their factor loadings are usually fixed to determine the type of hypothesized change captured by the latent factors. Here, the repeated measures of well-being were modeled using a quadratic LGCM. Change over time is indicated by three latent factors, an intercept factor (I) capturing individual differences at a given point in time (at time of death), a linear slope factor (S) capturing individual differences in linear rate of change in well-being, and a quadratic change factor (Q) capturing accelerations in the rate of change in well-being, and a set of unique residual factors $\left(\epsilon_{1}\right.$ to $\left.\epsilon_{M}\right)$ capturing otherwise unexplained occasion-specific differences.

The mean vector, $\boldsymbol{\mu}$, and the covariance matrix, $\boldsymbol{\Sigma}$, of the observed variables are a function of factor loadings, $\boldsymbol{\Lambda}$, a latent factor covariance matrix, $\boldsymbol{\Psi}$, and a residual factor covariance matrix, $\boldsymbol{\Theta}$ (e.g., Bollen, 1989): 


$$
\begin{aligned}
& \boldsymbol{\Sigma}=\boldsymbol{\Lambda} \boldsymbol{\Psi} \boldsymbol{\Lambda}^{\prime}+\boldsymbol{\Theta} \\
& \boldsymbol{\mu}=\boldsymbol{\Lambda} \boldsymbol{v}
\end{aligned}
$$

Under the assumption of homoscedastic and uncorrelated residual errors $\left(\sigma_{\epsilon t}^{2}=\sigma_{\epsilon}^{2}\right)$, and the intercept anchored at participants' year of death, the matrices for a quadratic LGCM are

$$
\begin{gathered}
\boldsymbol{\Lambda}=\left[\begin{array}{ccc}
1 & T-1 & (T-1)^{2} \\
1 & T-2 & (T-2)^{2} \\
\vdots & \vdots & \vdots \\
1 & 0 & 0
\end{array}\right] \\
\boldsymbol{\Psi}=\left[\begin{array}{ccc}
\sigma_{I}^{2} & \\
\sigma_{I S} & \sigma_{S}^{2} & \\
\sigma_{I Q} & \sigma_{S Q} & \sigma_{Q}^{2}
\end{array}\right] \\
\boldsymbol{v}=\left[\begin{array}{l}
\mu_{I} \\
\mu_{S} \\
\mu_{Q}
\end{array}\right] \\
\boldsymbol{\Theta}=\left[\begin{array}{ccc}
\sigma_{\epsilon}^{2} & 0 & 0 \\
0 & \ddots & 0 \\
0 & 0 & \sigma_{\epsilon}^{2}
\end{array}\right]
\end{gathered}
$$

where $T$ is the number of equidistant measurement occasions and the estimated parameters include the residual error variance, $\sigma_{\epsilon}^{2}$, the average well-being at death, $\mu_{I}$, the extent of individual in well-being at death, $\sigma_{I}^{2}$, the average linear rate of change, $\mu_{S}$, the extent of individual differences in that rate of change, $\sigma_{S}^{2}$, the average quadratic rate of change, $\mu_{Q}$, the extent of individual differences in that rate of change, $\sigma_{Q}^{2}$, and the covariances of the latent intercept, linear, and quadratic slope, $\sigma_{I S}, \sigma_{I Q}$, and $\sigma_{S Q}$. This quadratic LGCM was estimated (within the SEM Trees framework described below) using full information maximum likelihood (FIML), which yields unbiased estimates when data are missing completely at random (MCAR; e.g., when missing is only due to study protocol) or missing at random (MAR; Neale, 2000; Rubin, 1976).

Structural Equation Model Trees. Traditional SEM analyses assume sample homogeneity in a sense that each person adheres to the same specification and parameterization of the model. For example, a common assumption is that all individuals in the sample are 
adequately represented by a single quadratic LGCM. When heterogeneity is assumed to be present and unobserved, Growth Mixture Models (GMM; e.g.,Muthen, 2001) are often used to retrieve a clustering structure of participants' growth trajectories. As such, GMMs and other related techniques that invoke learning of hidden structure in time series data (e.g., Brandmaier, 2015) can be useful for generating hypotheses about differences in change processes (see Ram \& Grimm, 2009). As an extension to GMM, predictors of latent class group membership may be included to inform the estimation of latent class membership. This procedure requires an a priori choice of variables predicting group membership. The chosen predictors in a GMM can then be specified as linear and additive effects on the group membership and - unless explicitly specified - GMM does not allow for interactions among them. In this study, we use SEM Trees (SEM Trees; Brandmaier et al., 2013), which are a combination of SEM and decision trees to select among a heterogeneous set of potential predictors. Trees allow examining non-linear associations between predictors and outcomes and allow detection of interactions among predictors. They achieve this by recursively splitting the outcome space into piecewise homogeneous areas, which - in principle - allows estimating arbitrary functional forms. This is in contrast to linear models that are restricted to linear relations and a priori selected interactions. SEM Trees were proposed as a data-analytic tool that allows an exploratory search for predictors of differences in an initially theory-guided, multivariate model as outcome. By specifying the model of terminal decline in well-being as the SEM-based quadratic LGCM described above, SEM Trees allow for identification and examination of predictors, which we henceforth refer to as correlates to emphasize that they may not necessarily serve as antecedents of decline but rather accompaniments of differences in terminal decline trajectories.

SEM Trees are decision trees, similar to classification and regression trees (CART; Breiman, Friedman, Stone, \& Olshen, 1984), which recursively partition a sample into subgroups, such that, with respect to the outcome, participants within the subgroups are maximally similar to each other and the subgroups themselves maximally different from each 
other. Whereas standard CART analyses feature univariate outcomes, SEM Trees are modelbased trees, that is, each leaf in a SEM tree represents a multivariate model (e.g., a quadratic LGCM) with a unique set of parameter estimates. The criterion to determine the best split in each leaf is based on a likelihood-ratio test of differences between the groups resulting from a given split (Brandmaier et al., 2013). At each leaf, the tree is only further split if the likelihood ratio test indicated a significant group difference after Bonferroni-correction for multiple testing. We note that each potential correlate is evaluated only on the data available for that specific variable. In our case, for example, a potential split on the root of the tree for disability is based on the entire sample (because we have no missing data for disability), whereas a potential split for perceived control is based only on the 1,744 participants for whom data on this variable were available.

Structural Equation Model Forests. We complement the single-tree analysis with a SEM Forest analysis (Brandmaier et al., in press). SEM forests are ensembles of SEM trees, with each tree being based on a randomly permuted sample of the original data, and allow for a more robust quantification of variable importance - the impact of a given variable as an individual correlate together with its effect in multivariate interaction with all other potential correlates. Calculating variable importance from only a single tree has two important drawbacks: (a) from two or more highly correlated but equally predictive variables, only a single must be chosen for each decision node in a tree and we would have no means to accurately estimate importance for the variable left out, and (b) we would evaluate only the specific conditional effects of variables along the paths in a tree but there may be other conditional effects to consider. Averaging variable importance over resampled trees in a forest allows us to quantify the effect of a variable of interest across a diverse set of interactions. From an ANOVA perspective, this is similar to a compound measure of the main effect of a variable and all its possible interactions. Variable importance allows us to rank-order potential correlates of differences in the outcome and to derive relative importance among correlates. In particular, the 
variable importance statistic, VI, achieves this goal by estimating for each correlate the impact of its absence on the predictive accuracy of the whole forest, thereby removing the effect of a variable and its interactions when making a forest-based prediction (Brandmaier et al., in press). In sum, extension from SEM Tree to SEM Forest and the quantification of variable importance enables us to evaluate the set of candidate correlates with respect to the role each variable plays in predicting differences in terminal decline trajectories in a more robust and rigorous manner than a single tree. We employed SEM forests with 1,000 trees, subsampling as resampling procedure for cases and randomly sampling two potential correlates at each node of the tree (see Brandmaier et al., in press for details).

Equifinality and Multifinality. Further interpretation of the SEM Tree is facilitated by two additionnal measures. In theoretical discussions of development, equifinality and multifinality are often used to describe pathways of complex behavioral change (Sroufe, 1997). In general systems theory (Von Bertalanffy, 1969), multifinality refers to a scenario in which similar initial conditions lead to dissimilar outcomes, and equifinality describes a scenario in which the same or a similar outcome is reached through a variety of different developmental pathways and/or initial conditions. With some caution, trees containing variables that indicate individuals' differential experiences, like the negative life events and burden, allow for an interpretation of the tree in terms of individuals' developmental pathways (Scott, Whitehead, Bergeman, \& Pitzer, 2013). The specific path from the root to a leaf that is followed when classifying an individual case may be interpreted as a description of that individual's "life experience" in a broader sense (spanning socio-demographic, physical health and burden, and psychosocial characteristics). Note, however, that the selection criterion of variables is not reflecting a temporal or causal ordering, but merely a statistical one. We propose a heuristic approach to quantify the (dis)similarity of subsamples as represented by the leafs of a tree with measures drawing upon the ideas of multi- and equifinality. 
Taking a cross-sectional perspective, we quantify multifinality (same "life experiences", different outcome) as the extent of variability in well-being at the end of life within each leaf of the tree, specifically, the magnitude of individual differences in terminal well-being (i.e., the random effect of intercept, $\sigma_{I, i}^{2}$ ) in each leaf of the tree. As such, the proposed metric quantifies differences in the outcome (well-being) at the year of death instead of differences in the trajectories. Similar to a measure of explained variance, we normalize this value with the total observed individual differences of a non-tree model derived from the entire sample $\left(\boldsymbol{\sigma}_{\boldsymbol{I}, \boldsymbol{r o o t}}^{2}=\right.$ 172.8). We formalize equifinality (different "life experiences", same outcome) as the similarity of well-being at the end of life across pairs of leafs. To this end, we employ a measure that is inversely proportional to the standardized difference of intercept means in terminal well-being in a Cohen's $d$ metric. Formally, we define $M_{i}$ to be a measure for the multifinality of leaf $i$ and $E_{i j}$ a measure of the pairwise equifinality of two leafs $i$ and $j$.

$$
\begin{gathered}
M_{i}=\max \left(0, \frac{\sigma_{I, i}^{2}}{\sigma_{I, \text { root }}^{2}}\right) \\
E_{i j}=1-\min \left(1, \frac{\left|\mu_{I, i}-\mu_{I, j}\right|}{s d\left(\sigma_{I, i}^{2} \sigma_{I, j}^{2}\right)}\right)
\end{gathered}
$$

with $s d$ being a function calculating the pooled standard deviation based on the two leaf's random effect estimates of the intercept $\sigma_{i}^{2}$ and $\sigma_{j}^{2}$ :

$$
s d\left(\sigma_{i}^{2}, \sigma_{j}^{2}\right)=\sqrt{\frac{\left(N_{i}-1\right) \sigma_{i}^{2}+\left(N_{j}-1\right) \sigma_{j}^{2}}{N_{i}+N_{j}-2}}
$$

Both measures were defined such that they range from zero to one, with higher values representing larger degrees of multifinality and equifinality, respectively. Multifinality of zero is achieved in a leaf for which the variability of the intercept is zero - when there is no variability between persons in a leaf. A multifinality of one is obtained if the individual differences are equal in a leaf and a root-only model in which the sample is assumed homogenous (i.e., no subgroups). Pairwise equifinality is zero is when there are large differences in the average wellbeing at the end-of-life between individuals of two leafs. Pairwise equifinality is one when there 
is no difference between average well-being (or very small differences with very large variances). Note that large values of equifinality indicate a similarity across a pair of leafs on average but not necessarily that everybody across the pair of leafs shares the same outcome; persons in both pairs could still be highly variable in their outcomes (indicated by a large multifinality).

\section{Results}

Structural Equation Model Trees. For illustration of how the SEM Tree works and can be used to identify individual differences in terminal decline of well-being, we first analyzed the sample with a single decision tree. Results of the full tree are reported in Table 3 . The full tree has 12 different paths to leafs with combinations of diverse correlates. To ease its interpretation, we will discuss the results starting with a sub tree pruned to the first two levels (that is, a maximum of two decision nodes to reach a leaf). We proceed by inspecting a further level of interaction in a three-level tree and close with a broader look at the full tree.

As can be obtained, the best split of the sample at a first level was given by the social participation variable $\left(\chi^{2}=151.2\right)$, separating participants with low social participation $(n=1,924$ with social participation $<1.125$ on a 1 to 4 , higher $=$ more scale) from those with moderate to high social participation ( $n=1,968$, with social participation $\geq 1.125$ ). For individuals with low social participation, disability $\left(\chi^{2}=91.3\right)$ was the strongest correlate of differences in terminal decline at the second level. In contrast, for individuals with moderate to high social participation, we found hospitalization $\left(\chi^{2}=142.3\right)$ as strongest correlate. A graphic representation of the tree (dendrogram) showing the full tree pruned to the first two levels is shown in Figure 1. The inner nodes are decision nodes that can be followed to leaf nodes, which contain the estimates for the different subgroups. Using the fixed-effect estimates of the LGCMs in each leaf, we plotted in Figure 2 the prototypical trajectories (that is, model-predicted mean curves) of terminal decline for the four subgroups derived from the two-level tree. As can be obtained from thick lines representing average trajectories of the two groups, the split on social 
participation separated the low social participation group who reported lower levels of wellbeing and experienced steep terminal decline in well-being from the moderate to high social participation group who had relatively high levels of well-being and experienced less steep declines in well-being. Within these two groups, the next decision node in the tree - disability (yes, no) for the socially inactive and hospitalization (yes, no) for the socially active - splits each group again. Among individuals with low social participation (left Panel), those who had not experienced disability maintained a considerably higher level of well-being all the way until death (by some $\left.0.5 S D, \mu_{I}=43.1\right)$ than those who were disabled at some point in their lives $\left(\mu_{I}=\right.$ 36.8). Similarly, among individuals with moderate to high social participation (right Panel), those who had spent considerable time in the hospital reported considerably lower levels of latelife well-being and experienced particularly steep well-being declines relative to those not hospitalized.

We had chosen to anchor the intercept at the year of death so as to allow interpreting the intercept variance as a measure of between-person differences in terminal well-being at the time of death. Individuals in each leaf of the tree share a set of specific "life experiences" in the sense that they were on the same side of the cut-points at each node. Similarly, there may be evidence for equifinality if different terminal nodes in the tree exhibit similar end-of-life levels of wellbeing. For illustration purposes, Table 4 shows estimates of multifinality and equifinality for the tree pruned to the first two levels. Higher scores correspond to higher degrees of equi- and multifinality. Rows and columns represent the four leafs of the tree pruned to the first two levels. Values on the diagonal represent multifinality, that is the degree to which individuals who share the same paths on the tree are dissimilar. Values on the off-diagonal represent equifinality, that is the degree to which individuals at the corresponding two different developmental branches of the tree are similar to one another. At a purely descriptive level, these results allow us to evaluate the variability between participants within and across leafs of a tree. We find the largest equifinality $(0.99)$ between individuals with low social participation 
and disability and individuals with high social participation and hospitalization. This may suggest that there is no unconditional association of social participation with well-being, but in fact a negative compensatory role of health-related events and social participation. That is, the positive effect of high social participation is lessened with health-related negative events. Furthermore, we found the lowest multifinality score (0.04) in the group with low social participation and disability and the highest score $(0.15)$ in the high social participation and hospitalization group. Again, at a purely descriptive level, we cautiously infer that there are more unexplained individual differences in the group with high social participation, and we would expect further variables to play a role in explaining the differential development, more so than for the group with low social participation.

In the next step, we considered a third level of the SEM tree. Results are reported in Figure 3 and suggest further splits as sub-branches of the correlate disability by perceived control with a cut-point at around its median (2.625). A further sub-decision for those who were not hospitalized is a person's disability status. In conclusion, the first three levels of the tree show interactions of physical health and burden factors with psychosocial variables.

The full, unpruned tree has a height (defined as the number of decisions on the longest branch) of five and twelve leafs. At this level, no further significant splits of the branches were found (at a significance level of 0.01 after Bonferroni-correction). Candidate correlates appearing after the first three levels were sex, age at death, religion, and social goals. The full tree is shown in tabular form in Table 5. Each row corresponds to a leaf of the tree and each column from the set labeled "correlates" shows the observed average value people in the respective row have. If there is no value, the respective correlate was not part of the branch from the root to the leaf and, thus, the value of that correlate is not important to describe the subgroup. The three columns on the right labeled "fixed effects" show the mean intercept at age of death, $\mu_{I}$, and linear and quadratic rate of change in well-being, $\mu_{S}$ and $\mu_{Q}$. A graphical illustration of the average trajectories associated with each leaf is given in Figure 5. It can be 
obtained that there are considerable differences both in level of well-being at the end of life and in how people reach different end-points, that is, in the shape of terminal decline trajectories. In particular, we find that trajectories not only differ in the steepness and acceleration of decline but do also cross. This finding strengthens the notion that analyses should aim at fully understanding the underlying developmental processes that lead to individual differences in end points.

Structural Equation Model Forests. SEM Forest analyses allow for an accurate comparison of the candidate variables' importance for predicting individual differences in terminal decline in well-being. These analyses revealed findings largely consistent with those obtained in the single-tree analysis. Forest results represent averages over hundreds of trees and, thus, allow a more concise quantification of the total effect of a variable for the prediction of differential trajectories across individuals. In looser terms, forests allow for the quantification of variable importance in the sense of a variable's main effect and all possible interactions. Variable importance was calculated for all candidate variables. The results are shown in Figure 4. Inference tests on variable importance typically depend on forest parameters, particularly the number of trees, and are thus meaningless. Therefore, descriptive statistics of the correlates' influences are advised rather than relying on overpowered inference statistics (Strobl, Malley, \& Tutz, 2009). The top five variables with the largest influence on late-life well-being and terminal decline were - from large to small - disability, hospitalization, social participation, control beliefs, and social goals. All five indicators appeared in the single tree described above. Reliable estimates of importance were not obtained for death of parents, divorce, and income losses $>3000$ because these variables have not appeared in any single tree. Reasons for this can be either that these variables have a marginal association with well-being or that they have a low incidence rate. Following Strobl et al. (2009), we use the term non-informative variables to refer to constructs whose variable importance rating is within the range of negative estimated importance, which reflects random variation around the true zero importance. 


\section{Discussion}

Our major objective in the current study was to identify multi-way (nonlinear) constellations of correlates that are associated with individual differences in late-life well-being trajectories. Applying SEM Trees and SEM Forests to up to 25-year annual longitudinal data obtained from 4,404 now-deceased participants of the nationwide SOEP study revealed that physical health factors play a major role for terminal decline in well-being, but do so in interaction with psychosocial characteristics, such as social participation. For example, for people with low social participation, disability emerged as the strongest correlate of differences in late-life well-being trajectories. In contrast, for people with high social participation, the differentiator among high vs. low and stable vs. declining late-life well-being groups was having spent considerable time in the hospital. We corroborated these results with Variable Importance measures derived from resampled SEM Trees in a SEM forest that provide robust and comparative indicators of the total interactive effects of variables for differential late-life change. We discuss benefits and limitations of our approach and consider our findings in the context of other reports about protective and risk factors of terminal decline in well-being.

\section{Multi-Indicator Constellations of Physical Health and Psychosocial Correlates}

Our analyses corroborate the contention that individual differences in the often steep and accelerating end-of-life declines in well-being are associated with impairments and losses of physical health (Roberts, Dunkle, \& Haug, 1994). However, none of the burden factors emerged among the top five factors with the largest variable importance ratings and partner-related negative life events (death, hospitalization, or disability) were not distinguishable from the expected random variation. It is well possible that low prevalence rates of these events (no more than $1.1 \%$ ) contributed to our finding that, for example, the variables never occurred in any tree of a forest. Of note is also that age (at death), sex, and education that are each often identified as relevant correlates of mortality hazards and well-being (see Gerstorf \& Ram, 2013; Vaupel, 2010) were not among the top five in the variable importance rating, probably because the 
relevant profiles identified here reflect some of the major ways in which these factors operate to shape late-life well-being. We found some evidence for the relevance of religious activity because one of the leaves of the tree reported in Table 5 was split by religious activity and it ranked sixth in variable importance with still almost half the importance of disability. Such a finding is consistent with the idea that religious beliefs, worldviews, and activity may act as a buffer against stress and thereby contribute to well-being (Ellison, 1991). Our finding that social participation and perceived control were both part of the first leaves of the tree and among the top five variable importance (with social participation having $80 \%$ of the importance of the top correlate, disability, and perceived control having 53\% of the top correlate) ratings underscores earlier reports of the relevance of these variables for outcomes of successful aging (Baltes \& Baltes, 1986) and late-life well-being (Gerstorf et al., 2014; Gerstorf et al., 2016; Wallace et al., 2002).

With the current project, we corroborate and extend earlier reports (including our own) in several major ways. Prior analyses of terminal decline have more or less exclusively focused on average trends and single predictors of individual differences from this trend. This line of nomothetic analyses has shown that physical health conditions and morbidity (Berg, Hassing, Nilsson, \& Johansson, 2009; Burns et al., 2014; Gerstorf et al., 2013), perceived control (Berg et al., 2011; Gerstorf et al., 2014), and social integration (Gerstorf et al., 2016; Windsor et al., 2015) are relevant correlates of late-life well-being. Moving several steps forward, the current report does not target these correlates one by one, but makes use of an analytic technique that acknowledges and models (based on statistical and not on a priori decisions) how these variables are involved in, interact with, and operate conjointly in multi-indicator ensembles that may be unique to subgroups of participants who share similar outcomes. In doing so, we corroborate that physical health factors play a major role for late-life well-being decline, but do so in interaction with psychosocial characteristics such as social participation. To illustrate, for people with low social participation, disability emerged as the strongest correlate of differences in late- 
life well-being trajectories. However, for people with high social participation, whether or not an individual had spent considerable time in the hospital differentiated high vs. low and stable vs. declining late-life well-being. We speculate that differences in temporal horizon and reversibility of physical health conditions underlies at least part of the effect of why hospital stays (an often shorter-term and reversible life condition) emerged as important for late-life well-being among socially active people, whereas it was physical disability (an often long-term and less reversible life condition) that emerged as particularly relevant among rather socially inactive people. At a more general level, we infer from the interactive structure of the correlates that no single variable alone is sufficient to describe the pronounced individual differences in both late-life well-being and shape of terminal decline across subgroups as retrieved from the SEM Tree, but that the variables must be interpreted as interactive constellations of risk and protective factors. In the current study, we thus extend these earlier reports to directly demonstrate the importance of the interplay between psychosocial factors of perceived control and social participation and poor physical health.

Our approach may also be seen as an extension to the work of Singer, Ryff, Carr, and Magee (1998). The authors proposed an exploratory approach to derive decision rules over events in life histories to predict mental health outcomes. In their work, a combination of manual and automatic variable selection was proposed to derive at individual decision rules. As a potentially fully automated approach for generating pathways, they noted that decision trees may be a useful alternative approach. In support of this idea, we particularly value trees and forests as a tool that a) guides us in theory development by pointing us to interesting and unexpected effects in our empirical data, and b) may provide a predictive baseline model challenging purely theory-driven models for reconsideration (Brandmaier et al., in press). We note that decision trees had previously been used to examine the variables best suited to describe individual differences in well-being. For example, Wallace et al. (2002) had investigated differences in later life well-being with tree analyses of cross-sectional data. Two of their 
findings for compensatory associations were that (i) low perceived control did not show the typical association with compromised well-being when people rated their physical health as good and (ii) individuals with low perceived control combined with high social coping reported above-average well-being. These findings align with our result, from both the single tree and the forest analyses, that social participation, perceived control, and health-related burden factors are main driving forces of end-of-life well-being. We are aware of only one earlier report to examine subgroup differences in terminal decline in well-being. Specifically, Burns, Byles, Magliano, Mitchell, and Anstey (2015) had identified five different classes of women with distinct terminal decline trajectories in the Australian DYNOPTA study. Unfortunately, participants in that study were examined at a maximum of four waves only and an average of six years before death. As a consequence, very few data points were available in the year(s) immediately prior to death when terminal declines are expected to occur. In the current study, we expand these previous reports by using SEM trees derived from up to 25 annual waves of longitudinal data, with about four fifths of the sample providing one or more data points in their last two years of life. The trees aim at understanding terminal decline in well-being and provided for consideration of the "outcome" as a longitudinal trajectory (rather than a single well-being score). We also used a novel model-based random-forest-type (Brandmaier et al., in press) approach to accommodate the potential instability of single-tree analyses.

SEM Trees are particularly useful to explore correlates of individual differences in change because they allow an exploration of correlates for differences in a multivariate model formalizing an initial theoretical understanding (here, terminal decline trajectories of wellbeing). However, single trees are known to be susceptible to small perturbations of the original data set and suffer from suppression effects when correlates covary (Brandmaier et al., in press; Breiman, 2001). SEM Forests address these issues by generating perturbed trees and assessing variable importance as average over all trees in a forest. Thus, it is not surprising when the order of variable importance in forests and trees slightly diverges. We believe that the forest approach 
better addresses variable importance than any single tree. Nevertheless, a single tree can complement a forest analysis because it shows the conditionally best splits in the sample and, thus, a particular instance of an interaction structure and how those variables may shape the outcomes. Variable importance in model-based forests is by definition sign free, and does not indicate the direction of the effect or what parameters in the outcome model are being influenced (e.g., intercept or slope). Against this backdrop, findings from SEM tree and forests analyses remarkably converge in the current set of analyses.

\section{Limitations and Outlook}

In closing, we note several limitations of our study. First, a limitation of the method being applied here is the size of the trees. The small trees are much closer to the bivariate models that were used as a backdrop for suggesting that trees are a useful method, and likely the full value of using SEM trees will be obtained when scaling up to larger trees. The most interesting splits are probably found when relatively heterogeneous groups are split and the prime question is which constellation of correlates describes the split groups best. It is in this sense that recursive partitioning methods are useful tools towards theory generation, and the current report is one step towards that end. We also note that our current consideration of trajectories allows for a better understanding of how well-being evolves late in life and is, thus, more informative than cross-sectional analyses of well-being at some end point (e.g., the year before death). Alternative approaches of analysis may focus solely on the slope as outcome and specifically target correlates of isolated change. However, SEM Trees currently do not allow for variable selection based on sub sets of model parameters. Another point to be noted about our modeling efforts is that we deem it particularly important that the trees not be considered as a simple flow-chart, particularly, in the sense that the ordering along a path is not representing a temporal or even causal ordering of events, but rather a statistical ordering only. Furthermore, we advise against a reification of the groups resulting from a single tree; specifically when continuous variables are split, the split point represents a point of maximum separation (in an 
information-theoretic sense) but may not necessarily reflect a true dichotomy. When averaging across trees in a forest, the same variable may come up with different optimal cut points in each tree, as each variable plays out their tree-specific conditional effect; there is no necessity that cut points converge to a single point. Our model is longitudinal in the outcome and - depending on the predictors - cross-sectional or longitudinal. On both sides, we use a model to derive a higher-level description of the underlying processes. In the outcomes, we use chronometric factors representing different linear and curvilinear change forms. On the predictor side, we use either single snapshots (cross-sectional) or aggregate measures over time (longitudinal). Treating all correlates as time-varying would have unfortunately gone considerably beyond the capabilities of the data at hand. As a consequence, we cannot draw inferences about the temporal ordering between variables and about compensatory or cumulative effects.

A second central limitation of the study is that our outcome variable is based on a single item (nervertheless, this outcome variable is used and analyzed broadly in psychology). The psychometric properties of single-item measures are lower than those of comprehensive multiitem or multi-scale measures and may not be very sensitive to subtle changes in the underlying phenomenon. As such, the measure used here may have constrained the range of variability observed (see Gerstorf et al., 2014). Another measurement limitation is that well-being was assessed on a 11-point Likert scale and must, strictly speaking, be analyzed by models of ordinal outcomes. However, it is common practice to model ordinal outcomes using normal-theory methods, especially when a Likert scale with several points is used (for instance, Wallace et al., 2002, used CART for continuous prediction of a 13-point scale). Potential dangers of the continuous approximation are biases in coefficients, standard errors, and statistical power. When there are many categories and category distributions are not excessively normal, arising bias may be acceptable (see Bauer \& Sterba, 2011). We also acknowledge that our indicators of health only tap into fractions of the larger construct space and primarily index physical limitations and health-care utilization. In a similar vein, it would have been highly instructive to 
explore the utility of additional sets of correlates. For example, our analyses only made use of what one could consider negative life events and burden, but our models did not include the age at which those negative life events had occurred, the frequency of negative life events, or positive events that may have contributed to stable well-being and successful aging. Including further sets of correlates or using a design that obtains data in closer proximity to death may result in identifying other constellations of variables to be most relevant for terminal decline in well-being.

Third, for our analysis of burden, we had opted for a parsimonious approach and collapsed occurrences of negative life events into a dichotomous score of not having experienced the event or as having experienced the event, disregarding the specific year (age) the event happened and if the event happened more than once. Such dichotomous indicators of negative life events correspond to the dichotomous decisions in a decision tree approach, but neglects the exact timing and serial, potentially cumulative nature of effects. For example, Luhmann and Eid (2009) found that experiencing a given major life event (e.g., unemployment) a second or third time is associated with more pronounced reactions relative to the first experience. As a consequence, future analyses should aim at including additional event-related features (e.g., simple lifetime count of negative life events) and more closely modeling the dynamics of the change processes in both the time-varying outcome and the time-varying correlates. It may be promising to investigate the influence of correlates as random shocks to the change process, as can be discerned in designs that obtain intensive longitudinal data collected at denser intervals (e.g., weeks, days, hours).

Finally, we have proposed summary measures of differences in terminal well-being across subgroups in a tree that draw upon ideas of developmental equi- and multifinality. These measures are currently merely descriptive statistics to address similarity and dissimilarity of individuals with equal or different correlates as chosen by the tree. In its current form, the measures are limited to a comparison of terminal well-being instead of accounting for 
differences in the actual developmental trajectories. Further work is needed to elaborate upon these ideas and to devise statistical tests that allow rigorous testing of differences across subgroups. For example, likelihood ratio tests of group differences may serve as a further means to assess similarity between either end-points of well-being or between complete trajectories. We note that SEM Trees and forests, as instances of the model-based recursive-partitioning paradigm, have emerged only in the last few years, and thus are still evolving in terms of availability, computational efficiency, and user-friendliness. However, the method has proven useful to expand upon earlier cross-sectional results of individual differences in well-being changes using longitudinal data and a diverse set of potential correlates. A particular advantage of SEM Trees is their ability to provide parametric multiple-group models allowing for immediate confirmation of the tree models in replication studies or different samples. So far, SEM Trees do not impute missing data in the correlates but rather ignore missing cases in the evaluation of potential splitting variables. This biases variable selection towards variables with less missing data. Strictly, we evaluated the observed predictive importance of variables instead of the true potential (had they been fully observed). Future work must address this issue.

\section{Conclusion}

We have successfully replicated and expanded previous reports of correlates of wellbeing using novel methods combining theory-driven statistical modeling and data-driven exploratory modeling. We have shown how SEM trees and forests can be used to support empirical research to make comprehensive use of the data by searching a large covariate space to allow modification of one's initial, theory-driven hypotheses. Exploratory approaches are probably especially useful for research on well-being for which outcomes and pathways are often complex, highly interactive, and non-linear. We hope that similar analysis approaches with different models and observational studies will help to shed light on the multifaceted constellations of factors that may serve as risk for and protective factors against terminal decline in well-being. 


\section{References}

Antonucci, T. C. (2001). Social relations: An examination of social networks, social support, and sense of control. In J. E. Birren \& K. W. Schaie (Eds.), Handbook of the psychology of aging (pp. 427-453). San Diego, CA: Academic Press.

Baltes, P. B., \& Baltes, M. M. (1986). The Psychology of Control and Aging. Hillsdale, NJ: Lawrence Erlbaum Associates.

Baltes, P. B., \& Smith, J. (2003). New frontiers in the future of aging: from successful aging of the young old to the dilemmas of the fourth age. Gerontology, 49(2), 123-135. doi:10.1159/000067946

Bauer, D. J., \& Sterba, S. K. (2011). Fitting Multilevel Models With Ordinal Outcomes: Performance of Alternative Specifications and Methods of Estimation. Psychological Methods, 16(4), 373-390. doi:10.1037/A0025813

Berg, A. I., Hassing, L. B., Thorvaldsson, V., \& Johansson, B. (2011). Personality and personal control make a difference for life satisfaction in the oldest-old: findings in a longitudinal population-based study of individuals 80 and older. European Journal of Ageing, 8(1), 13-20. doi:10.1007/S10433-011-0181-9

Bollen, K. A. (1989). Structural Equations with Latent Variables. Oxford, UK: John Wiley.

Brandmaier, A. M. (2015). pdc: An R Package for Complexity-Based Clustering of Time Series. Journal of Statistical Software, 67(5), 1-23. doi:10.18637/jss.v067.i05

Brandmaier, A. M., Prindle, J. J., McArdle, J. J., \& Lindenberger, U. (in press). Theoryguided Exploration with Structural Equation Model Forests. Psychological Methods.

Brandmaier, A. M., von Oertzen, T., McArdle, J. J., \& Lindenberger, U. (2013). Structural Equation Model Trees. Psychological Methods, 18(1), 71-86. doi:10.1037/A0030001

Brandmaier, A. M., von Oertzen, T., McArdle, J. J., \& Lindenberger, U. (2014). Exploratory Data Mining with Structural Equation Model Trees Contemporary issues in 
exploratory data mining in the behavioral sciences (pp. 96-127): New York: Routledge.

Brandstädter, J. (1999). Sources of resilience in the aging self: Toward integrating perspectives. In T. M. Hess \& F. Blanchard-Fields (Eds.), Social cognition and aging (pp. 123-141). San Diego, CA: Academic Press.

Breiman, L. (2001). Random forests. Machine learning, 45(1), 5-32. doi:10.1023/A:1010933404324

Breiman, L., Friedman, J., Stone, C. J., \& Olshen, R. A. (1984). Classification and regression trees: CRC press.

Brickman, P., \& Campbell, D. T. (1971). Hedonic relativism and planning the good society. In M. Appley (Ed.), Adaptation-level theory (pp. 287-305). New York, NY: Academic Press.

Brockmann, H., \& Klein, T. (2004). Love and death in Germany: The marital biography and its effect on mortality. Journal of Marriage and Family, 66(3), 567-581. doi:10.1111/J.0022-2445.2004.00038.X

Burkhauser, R. V., Giles, P., Lillard, D. R., \& Schwarze, J. (2005). Until death do us part: An analysis of the economic well-being of widows in four countries. Journals of Gerontology Series B-Psychological Sciences and Social Sciences, 60(5), S238-S246. doi:10.1093/geronb/60.5.S238

Burns, R. A., Byles, J., Magliano, D. J., Mitchell, P., \& Anstey, K. J. (2015). The utility of estimating population-level trajectories of terminal wellbeing decline within a growth mixture modelling framework. Social Psychiatry and Psychiatric Epidemiology, 50(3), 479-487. doi:10.1007/s00127-014-0948-3 
Burns, R. A., Mitchell, P., Shaw, J., \& Anstey, K. J. (2014). Trajectories of terminal decline in the well-being of older women: the DYNOPTA project. Psychology and Aging, 29(1), 44-56. doi:10.1037/a0035370

Carmel, S., Shrira, A., \& Shmotkin, D. (2013). The Will to Live and Death-Related Decline in Life Satisfaction. Psychology and Aging, 28(4), 1115-1123. doi:10.1037/a0034649

Carstensen, L. L. (2006). The influence of a sense of time on human development. Science, 312(5782), 1913-1915. doi:10.1126/science.1127488

Charles, S. T. (2010). Strength and Vulnerability Integration: A Model of Emotional WellBeing Across Adulthood. Psychological Bulletin, 136(6), 1068-1091. doi:10.1037/a0021232

Cohen, S., \& Wills, T. A. (1985). Stress, Social Support, and the Buffering Hypothesis. Psychological Bulletin, 98(2), 310-357. doi:10.1037//0033-2909.98.2.310

Diehr, P., Williamson, J., Burke, G. L., \& Psaty, B. M. (2002). The aging and dying processes and the health of older adults. Journal of Clinical Epidemiology, 55(3), 269-278. doi:10.1016/S0895-4356(01)00462-0

Diener, E., Suh, E. M., Lucas, R. E., \& Smith, H. L. (1999). Subjective well-being: Three decades of progress. Psychological Bulletin, 125(2), 276-302.

Dolan, P., Peasgood, T., \& White, M. (2008). Do we really know what makes us happy? A review of the economic literature on the factors associated with subjective well-being. Journal of Economic Psychology, 29, 94-122. doi:10.1016/j.joep.2007.09.001

Duncan, T. E., Duncan, S. C., \& Strycker, L. A. (2013). An introduction to latent variable growth curve modeling: Concepts, issues, and application: Routledge Academic.

Ellison, C. G. (1991). Religious Involvement and Subjective Well-Being. Journal of Health and Social Behavior, 32(1), 80-99. 
Ferrer, E., \& McArdle, J. (2003). Alternative structural models for multivariate longitudinal data analysis. Structural Equation Modeling, 10(4), 493-524. doi:10.1207/S15328007SEM1004_1

Ferrer, E., \& McArdle, J. J. (2010). Longitudinal modeling of developmental changes in psychological research. Current Directions in Psychological Science, 19(3), 149-154. doi:10.1177/0963721410370300

Fujita, F., \& Diener, E. (2005). Life satisfaction set point: Stability and change. Journal of Personality and Social Psychology, 88(1), 158-164. doi:10.1037/0022-3514.88.1.158

Gerstorf, D., Heckhausen, J., Ram, N., Infurna, F. J., Schupp, J., \& Wagner, G. G. (2014). Perceived Personal Control Buffers Terminal Decline in Well-Being. Psychology and Aging, 29(3), 612-625. doi:10.1037/A0037227

Gerstorf, D., Hoppmann, C. A., Löckenhoff, C. E., Infurna, F. J., Schupp, J., Wagner, G. G., \& Ram, N. (2016). Terminal decline in well-being: The role of social orientation. Psychology and Aging, 31(2), 149-165. doi:10.1037/pag0000072

Gerstorf, D., \& Ram, N. (2013). Inquiry into terminal decline: five objectives for future study. Gerontologist, 53(5), 727-737. doi:10.1093/geront/gnt046

Gerstorf, D., Ram, N., Estabrook, R., Schupp, J., Wagner, G. G., \& Lindenberger, U. (2008). Life satisfaction shows terminal decline in old age: Longitudinal evidence from the German Socio-Economic Panel Study (SOEP). Developmental Psychology, 44(4), 1148-1159. doi:10.1037/0012-1649.44.4.1148

Gerstorf, D., Ram, N., Lindenberger, U., \& Smith, J. (2013). Age and Time-to-Death Trajectories of Change in Indicators of Cognitive, Sensory, Physical, Health, Social, and Self-Related Functions. Developmental Psychology, 49(10), 1805-1821. doi:10.1037/a0031340 
Gerstorf, D., Ram, N., Mayraz, G., Hidajat, M., Lindenberger, U., Wagner, G. G., \& Schupp, J. (2010). Late-Life Decline in Well-Being Across Adulthood in Germany, the United Kingdom, and the United States: Something Is Seriously Wrong at the End of Life. Psychology and Aging, 25(2), 477-485. doi:10.1037/A0017543

Gruenewald, T. L., Mroczek, D. K., Ryff, C. D., \& Singer, B. H. (2008). Diverse pathways to positive and negative affect in adulthood and later life: An integrative approach using recursive partitioning. Developmental Psychology, 44(2), 330-343. doi:10.1037/00121649.44 .2 .330

Gruenewald, T. L., Seeman, T. E., Ryff, C. D., Karlamangla, A. S., \& Singer, B. H. (2006). Combinations of biomarkers predictive of later life mortality. Proceedings of the National Academy of Sciences of the United States of America, 103(38), 1415814163. doi:10.1073/Pnas.0606215103

Handley, T. E., Hiles, S. A., Inder, K. J., Kay-Lambkin, F. J., Kelly, B. J., Lewin, T. J., . . Attia, J. R. (2014). Predictors of Suicidal Ideation in Older People: A Decision Tree Analysis. American Journal of Geriatric Psychiatry, 22(11), 1325-1335. doi:10.1016/j.jagp.2013.05.009

Hannöver, W., \& Kordy, H. (2005). Predicting outcomes of inpatient psychotherapy using quality management data: comparing classification and regression trees with logistic regression and linear discriminant analysis. Psychotherapy Research, 15(3), 236-247. doi:Doi 10.1080/10503300512331334995

Headey, B. (2008). Life goals matter to happiness: A revision of set-point theory. Social Indicators Research, 86(2), 213-231. doi:10.1007/S11205-007-9138-Y

Headey, B., Muffels, R., \& Wagner, G. G. (2010). Long-running German panel survey shows that personal and economic choices, not just genes, matter for happiness. Proceedings 
of the National Academy of Sciences of the United States of America, 107(42), 1792217926. doi:10.1073/Pnas.1008612107

Herzog, A. R., \& House, J. S. (1991). Productive activities and aging well. Generations, 15, 49-54.

Infurna, F. J., Gerstorf, D., Ram, N., Schupp, J., Sprangers, M. A. G., \& Wagner, G. G. (2014). Linking Concurrent Self-Reports and Retrospective Proxy Reports About the Last Year of Life: A Prevailing Picture of Life Satisfaction Decline. Journals of Gerontology Series B-Psychological Sciences and Social Sciences, 69(5), 695-709. doi:10.1093/geronb/gbt055

Infurna, F. J., Gerstorf, D., Ram, N., Schupp, J., \& Wagner, G. G. (2011). Long-Term Antecedents and Outcomes of Perceived Control. Psychology and Aging, 26(3), 559575. doi:10.1037/A0022890

Jessen, F., Wiese, B., Cvetanovska, G., Fuchs, A., Kaduszkiewicz, H., Kolsch, H., . . Bickel, H. (2007). Patterns of subjective memory impairment in the elderly: association with memory performance. Psychological Medicine, 37(12), 1753-1762. doi:10.1017/S0033291707001122

Kitsantas, P., Kitsantas, A., \& Anagnostopoulou, T. (2008). A cross-cultural investigation of college student alcohol consumption: A classification tree analysis. Journal of Psychology, 142(1), 5-20. doi:10.3200/Jrlp.142.1.5-20

Kitsantas, P., Moore, T. W., \& Sly, D. F. (2007). Using classification trees to profile adolescent smoking behaviors. Addictive Behaviors, 32(1), 9-23. doi:10.1016/J.Addbeh.2006.03.014

Lachman, M. E. (2006). Perceived control over age-related declines: Adaptive beliefs and behaviors. Current Directions in Psychological Science, 15, 282-286. doi:10.1111/j.1467-8721.2006.00453.x 
Lachman, M. E., \& Weaver, S. L. (1998). The sense of control as a moderator of social class differences in health and well-being. Journal of Personality and Social Psychology, 74(3), 763-773. doi:10.1037//0022-3514.74.3.763

Lawton, M. P. (1983). Environment and other determinants of well-being in older people. Gerontologist, 23(4), 349-357. doi:10.1093/geront/23.4.349

Lemsky, C. M., Smith, G., Malec, J. F., \& Ivnik, R. J. (1996). Identifying risk for functional impairment using cognitive measures: An application of CART modeling. Neuropsychology, 10(3), 368-375. doi:10.1037//0894-4105.10.3.368

Lucas, R. E. (2007a). Adaptation and the set-point model of subjective well-being - Does happiness change after major life events? Current Directions in Psychological Science, 16(2), 75-79. doi:10.1111/j.1467-8721.2007.00479.x

Lucas, R. E. (2007b). Long-term disability is associated with lasting changes in subjective well-being: Evidence from two nationally representative longitudinal studies. Journal of Personality and Social Psychology, 92(4), 717-730. doi:10.1037/0022-

3514.92.4.717

Luhmann, M., \& Eid, M. (2009). Does It Really Feel the Same? Changes in Life Satisfaction Following Repeated Life Events. Journal of Personality and Social Psychology, 97(2), 363-381. doi:10.1037/A0015809

Lyubomirsky, S., \& Layous, K. (2013). How Do Simple Positive Activities Increase WellBeing? Current Directions in Psychological Science, 22(1), 57-62. doi:10.1177/0963721412469809

McArdle, J. J. (2013). Dealing with Longitudinal Attrition Using Logistic Regression and Decision Tree Analyses. In J. J. McArdle \& R. Gilbert (Eds.), Contemporary issues in exploratory data mining in the behavioral sciences (pp. 282--311). 
Meredith, W., \& Tisak, J. (1990). Latent curve analysis. Psychometrika, 55(1), 107--122. doi:10.1007/BF02294746

Mirowsky, J., \& Ross, C. E. (2007). Life course trajectories of perceived control and their relationship to education. American Journal of Sociology, 112(5), 1339-1382. doi: $10.1086 / 511800$

Moen, P. (1996). Gender, age, and the life course. In R. H. Binstock \& L. K. George (Eds.), Handbook of aging and the social sciences (4 ed.). San Diego, CA: Academic Press.

Mroczek, D. K., \& Spiro, A. (2005). Change in life satisfaction during adulthood: Findings from the veterans affairs normative aging study. Journal of Personality and Social Psychology, 88(1), 189-202. doi:10.1037/0022-3514.88.1.189

Muthen, B. (2001). Latent variable mixture modeling. New developments and techniques in structural equation modeling, 1-33.

Neale, M. C. (2000). Individual fit, heterogeneity, and missing data in multigroup sem. Modeling longitudinal and multiple-group data: Practical issues, applied approaches, and specific examples. Hillsdale, NJ: Lawrence Erlbaum Associates.

Palgi, Y., Shrira, A., Ben-Ezra, M., Spalter, T., Kavé, G., \& Shmotkin, D. (2014). AgeRelated and Death-Related Differences in Emotional Complexity. Psychology and Aging, 29(2), 284-296. doi:10.1037/a0036302

Palgi, Y., Shrira, A., Ben-Ezra, M., Spalter, T., Shmotkin, D., \& Kavé, G. (2010). Delineating Terminal Change in Subjective Well-Being and Subjective Health. Journals of Gerontology: Series B: Psychological Sciences and Social Sciences, 65(1), 61-64. doi:10.1093/Geronb/Gbp095

Pearlin, L. I. (1989). The Sociological-Study of Stress - Reply. Journal of Health and Social Behavior, 30(3), 269-269. doi:Doi 10.2307/2136959 
Pearlin, L. I., \& Schooler, C. (1978). The structure of coping. Journal of Health and Social Behavior, 19(1), 2-21.

Preacher, K. J. (2008). Latent growth curve modeling. Los Angeles u.a.: SAGE.

Ram, N., \& Grimm, K. J. (2007). Using simple and complex growth models to articulate developmental change: Matching theory to method. International Journal of Behavioral Development, 31, 303-316. doi:10.1177/0165025407077751

Ram, N., \& Grimm, K. J. (2009). Methods and Measures: Growth mixture modeling: A method for identifying differences in longitudinal change among unobserved groups. International Journal of Behavioral Development, 33, 565-576. doi:10.1177/0165025409343765

Roberts, B. L., Dunkle, R., \& Haug, M. (1994). Physical, Psychological, and Social Resources as Moderators of the Relationship of Stress to Mental-Health of the Very Old. Journals of Gerontology, 49(1), S35-S43. doi:10.1093/geronj/49.1.S35

Rubin, D. B. (1976). Inference and Missing Data. Biometrika, 63(3), 591-592. doi:10.1093/biomet/63.3.581

Schilling, O. K., Wahl, H. W., \& Oswald, F. (2013). Change in Life Satisfaction Under Chronic Physical Multi-morbidity in Advanced Old Age: Potential and Limits of Adaptation. Journal of Happiness Studies, 14(1), 19-36. doi:10.1007/s10902-0119313-3

Schmitz, N., Kugler, J., \& Rollnik, J. (2003). On the relation between neuroticism, selfesteem, and depression: Results from the national comorbidity survey. Comprehensive Psychiatry, 44(3), 169-176. doi:10.1053/Comp.2003.50033

Scott, S. B., Jackson, B. R., \& Bergeman, C. S. (2011). What Contributes to Perceived Stress in Later Life? A Recursive Partitioning Approach. Psychology and Aging, 26(4), 830843. doi:10.1037/a0023180 
Scott, S. B., Whitehead, B. R., Bergeman, C. S., \& Pitzer, L. (2013). Combinations of stressors in midlife: examining role and domain stressors using regression trees and random forests. J Gerontol B Psychol Sci Soc Sci, 68(3), 464-475. doi:10.1093/geronb/gbs166

Singer, B., Ryff, C. D., Carr, D., \& Magee, W. J. (1998). Linking life histories and mental health: A person-centered strategy. Sociological Methodology, Vol. 28 1998, 28, 1-51. doi:Doi 10.1111/0081-1750.00041

Sonquist, J., \& Morgan, J. (1964). The detection of interaction effects. A report on a computer program for the selection of optimal combinations of explanatory variables (35). Retrieved from Ann Arbor, MI:

Sroufe, L. A. (1997). Psychopathology as an outcome of development. Development and Psychopathology, 9(2), 251-268. Retrieved from $<$ Go to ISI>://WOS:A1997XE59500004

Strobl, C., Malley, J., \& Tutz, G. (2009). An Introduction to Recursive Partitioning: Rationale, Application, and Characteristics of Classification and Regression Trees, Bagging, and Random Forests. Psychological Methods, 14(4), 323-348. doi:10.1037/A0016973

Vaupel, J. W. (2010). Biodemography of human ageing. Nature, 464(7288), 536-542. doi:10.1038/nature08984

Vogel, N., Schilling, O. K., Wahl, H. W., Beekman, A. T. F., \& Penninx, B. W. J. H. (2013). Time-to-death-related change in positive and negative affect among older adults approaching the end of life. Psychology and Aging, 28(1), 128-141. doi:10.1037/a0030471

Von Bertalanffy, L. (1969). General system theory: Foundations, development, applications. New York: G. Braziller. 
Wagner, G. G., Frick, J. R., \& Schupp, J. (2007). Enhancing the Power of Household Panel Studies-The Case of the German Socio-Economic Panel Study (SOEP). Schmollers Jahrbuch, 127, 139-169.

Wallace, K. A., Bergeman, C. S., \& Maxwell, S. E. (2002). Predicting well-being outcomes in later life: An application of classification and regression tree (CART) analysis. In S. P. Shohov (Ed.), Advances in psychology research (Vol. 17, pp. 71-92). Hauppauge, NY: Nova Science Publisher.

Watson, D., \& Pennebaker, J. W. (1989). Health complaints, stress, and distress: exploring the central role of negative affectivity. Psychological Review, 96(2), 234-254.

Windsor, T. D., Gerstorf, D., \& Luszcz, M. A. (2015). Social resource correlates of levels and time-to-death-related changes in late-life affect. Psychology and Aging, 30(1), 136-148. doi:10.1037/a0038757 
Table 1

Sample descriptives for candidate correlates of terminal decline in well-being in the SOEP.

\begin{tabular}{lllll}
\hline Minimum & Median & VR & Maximum & $\begin{array}{c}\text { Proportion } \\
\text { Missing }\end{array}$ \\
\hline
\end{tabular}

Sociodemographic variables

$\begin{array}{lrrrrr}\text { Age at Death } & 18 & 76 & 14.33^{*} & 103 & 0 \\ \text { Sex } & 1 & 1 & 0.48 & 2 & 0 \\ \text { Education } & 7 & 10.5 & 0.66 & 18 & 0.02 \\ \text { Religion } & 1 & 2 & 0.5 & 4 & 0.25\end{array}$

Physical health and burden

$\begin{array}{llllll}\text { Disability }^{1} & 0 & 0 & 0.43 & 1 & 0 \\ \text { Disability }^{1}(\mathrm{P}) & 0 & 0 & 0.19 & 1 & 0 \\ \text { Hospitalization }^{1} & 0 & 0 & 0.16 & 1 & 0 \\ \text { Hospitalization }^{1}(\mathrm{P}) & 0 & 0 & 0.05 & 1 & 0 \\ \text { Unemployment }^{1} & 0 & 0 & 0.07 & 1 & 0 \\ \text { Unemployment }^{1}(\mathrm{P}) & 0 & 0 & 0.05 & 1 & 0 \\ \text { Death of parent }^{1} & 0 & 0 & 0.01 & 1 & 0 \\ {\text { Death }(\mathrm{P})^{1}}^{1} & 0 & 0 & 0.08 & 1 & 0 \\ \text { Divorce }^{1} & 0 & 0 & 0.01 & 1 & 0 \\ \text { Income loss }^{1}>1000 & 0 & 0 & 0.02 & 1 & 0 \\ \text { Income loss }^{1}>3000 & 0 & 0 & 0 & 1 & 0\end{array}$

Psychosocial characteristics

\begin{tabular}{lrrrrr} 
Social participation & 1 & 1.25 & 0.51 & 4 & 0.11 \\
Perceived control & 1 & 2.62 & 0.88 & 4 & 0.6 \\
Success goals & 2 & 5 & 0.72 & 8 & 0.43 \\
Social goals & 2 & 5 & 0.63 & 8 & 0.4 \\
Family goals & 2 & 7 & 0.69 & 8 & 0.41 \\
\hline
\end{tabular}

Note. $N=4,404$. Religious activity. $(\mathrm{P})=$ partner. ${ }^{1}=$ dichotomous variable, $\mathrm{VR}=$ Variation

Ratio, calculated as 1-(proportion of cases in mode), corresponds to the frequency of the less frequent category for dichotomous variables, ${ }^{*}=$ standard deviation is reported as measure of dispersion for continuous variables, Max = Maximum . 
Table 2

Intercorrelations among the candidate correlates of terminal decline in well-being in the SOEP.

\begin{tabular}{|c|c|c|c|c|c|c|c|c|c|c|c|c|c|c|c|c|c|c|c|c|}
\hline & 1 & 2 & 3 & 4 & 5 & 6 & 7 & 8 & 9 & 10 & 11 & 12 & 13 & 14 & 15 & 16 & 17 & 18 & 19 & 20 \\
\hline 1. Age at Death & & & & & & & & & & & & & & & & & & & & \\
\hline 2. Sex & .22 & & & & & & & & & & & & & & & & & & & \\
\hline 3. Education & -.13 & -.25 & & & & & & & & & & & & & & & & & & \\
\hline 5. Disability & -.03 & -.11 & .04 & -.03 & & & & & & & & & & & & & & & & \\
\hline 6. Disability $(\mathrm{P})$ & -.01 & .00 & -.01 & .04 & 18 & & & & & & & & & & & & & & & \\
\hline 7. Hospitalization & -.04 & -.03 & -.01 & -.03 & .25 & .07 & & & & & & & & & & & & & & \\
\hline 10. Unemployment $(\mathrm{P})$ & -.21 & -.05 & .01 & -.08 & .03 & .03 & .04 & .05 & .25 & & & & & & & & & & & \\
\hline 11. Death Parent & -.10 & -.03 & .03 & .00 & .03 & -.01 & 0 & -.02 & .11 & .05 & & & & & & & & & & \\
\hline 12. Death $(\mathrm{P})$ & .14 & .08 & -.04 & .06 & .05 & .19 & .05 & .16 & -.02 & -.01 & -.03 & & & & & & & & & \\
\hline 13. Divorce & -.12 & -.05 & .03 & -.04 & .01 & -.03 & .01 & -.01 & .13 & .05 & .02 & -.02 & & & & & & & & \\
\hline 14. Income Loss $>1000$ & -.11 & -.08 & .09 & .00 & -.02 & -.01 & .01 & -.01 & .06 & .05 & .06 & -.03 & .05 & & & & & & & \\
\hline 19. Social goals & -.10 & -.08 & .22 & .16 & .00 & .03 & -.01 & .01 & .02 & .02 & .03 & -.02 & .01 & .06 & .01 & .33 & .15 & .29 & & \\
\hline 20. Family goals & -.16 & -.14 & .09 & .10 & .03 & .14 & .00 & .06 & .05 & .07 & .02 & .00 & .02 & .07 & .03 & .12 & .08 & .28 & .31 & \\
\hline 21. Well-Being & .02 & -.06 & .09 & .12 & -.20 & -.03 & -.22 & -.04 & -.05 & -.05 & -.02 & -.04 & -.04 & .04 & .01 & .14 & .19 & .08 & .18 & .05 \\
\hline
\end{tabular}

Note. $N=4,404$. Religious activity. $(\mathrm{P})=$ partner. Intercorrelations are Spearman's rank correlation coefficient based on pairwise non-missing values (i.e., $n$ 's differ between table entries). Intercorrelations in bold are significantly different from zero at $p=.05$ (uncorrected). Well-being taken from the assessment at one year prior to death. 
Table 3

Descriptive statistics for subgroups of SOEP participants derived from the first two levels of the SEM Tree.

\begin{tabular}{|c|c|c|c|c|c|c|c|c|}
\hline \multirow[b]{3}{*}{ Model Estimates } & \multicolumn{4}{|c|}{$\begin{array}{l}\text { Low social participation } \\
\qquad(n=1,924)\end{array}$} & \multicolumn{4}{|c|}{$\begin{array}{l}\text { High social participation } \\
(n=1,968)\end{array}$} \\
\hline & \multicolumn{2}{|c|}{$\begin{array}{l}\text { No disability } \\
(n=1,034)\end{array}$} & \multicolumn{2}{|c|}{$\begin{array}{l}\text { Disability } \\
(n=890)\end{array}$} & \multicolumn{2}{|c|}{$\begin{array}{l}\text { No hospitalization } \\
\quad(n=1,646)\end{array}$} & \multicolumn{2}{|c|}{$\begin{array}{c}\text { Hospitalization } \\
(n=340)\end{array}$} \\
\hline & $M$ & $V A R$ & $M$ & $V A R$ & $M$ & $V A R$ & $M$ & $V A R$ \\
\hline Level of well-being before death & 43.1 & 12.6 & 36.8 & 12.9 & 44.9 & 12.3 & 36.7 & 12.1 \\
\hline Linear rate of change of well-being & -1.4 & 2.4 & -2.3 & 2.0 & -1.6 & 1.2 & -2.9 & 2.9 \\
\hline Quadratic rate of change of well-being & -0.1 & 0.0 & -0.1 & 0.0 & -0.1 & 0.0 & -0.2 & 0.0 \\
\hline Variables & $M$ & $S D$ & $M$ & $S D$ & $M$ & $S D$ & $M$ & $S D$ \\
\hline Age at death & 76.5 & 14.1 & 74.7 & 12.0 & 70.5 & 15.3 & 71.5 & 13.4 \\
\hline Sex (\% Women $)$ & 59.9 & & 46.3 & & 43.0 & & 38.2 & \\
\hline Years of education & 10 & 1.5 & 10.1 & 1.4 & 11.5 & 2.4 & 11.3 & 2.3 \\
\hline Perceived control & 2.5 & 0.4 & 2.4 & 0.5 & 2.7 & 0.5 & 2.6 & 0.5 \\
\hline
\end{tabular}

Note. Level and rates of change of well-being are derived from model-based estimates and are reported as estimated mean (M) and variance

(VAR) of the corresponding latent growth factors; level is centered at year of death. The remaining variables are sample mean ( $M)$ and standard deviations $(S D)$. Additional model parameters are shown in the leafs of the tree in Figure 1. 
Table 4

Estimates of Equifinality and Multifinality for the two-level tree based on SOEP data.

\begin{tabular}{|c|c|c|c|c|}
\hline & \multicolumn{4}{|c|}{ Node } \\
\hline & 1 & 2 & 3 & 4 \\
\hline 1. Low social participation \& no disability & 0.91 & & & \\
\hline 2. Low social participation \& disability & 0.51 & 0.96 & & \\
\hline 3. High social participation \& no hospitalization & 0.85 & 0.35 & 0.88 & \\
\hline 4. High social participation \& hospitalization & 0.49 & 0.99 & 0.33 & 0.85 \\
\hline
\end{tabular}

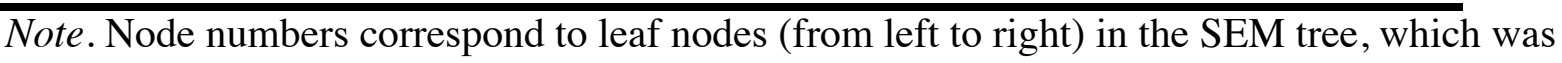
pruned to two levels. Values on the diagonal are indicated in bold and indicate multifinality, quantified as the magnitude of individual differences within a leaf. Values in the offdiagonals are pairwise measures of equifinality, quantified as the similarity (inversely proportional to a standardized difference of the means) of well-being in a pair of leafs. Higher values represent higher degrees of equi- and multifinality. 
Table 5

A tabular representation of the full SEM tree for differences in trajectories of terminal decline in well-being in the SOEP.

\begin{tabular}{|c|c|c|c|c|c|c|c|c|c|c|}
\hline \multicolumn{8}{|c|}{ Correlates } & \multicolumn{3}{|c|}{ Fixed Effects } \\
\hline $\begin{array}{c}\text { Social } \\
\text { participation }\end{array}$ & Disability & Hospitalization & Control & Age & Sex & $\begin{array}{c}\text { Social } \\
\text { goals }\end{array}$ & Religion & Intercept & Linear & Quadratic \\
\hline$<1.12$ & No & & $<2.54$ & & & & & 42.34 & -0.85 & -0.03 \\
\hline$<1.12$ & No & & $>=2.54$ & & men & & & 43.63 & -2.26 & -0.17 \\
\hline$<1.12$ & No & & $>=2.54$ & & women & & & 39.67 & -2.6 & -0.14 \\
\hline$<1.12$ & Yes & & $<2.44$ & & & & & 34.61 & -1.97 & -0.1 \\
\hline$<1.12$ & Yes & & $>=2.44$ & & & & & 38.56 & -2.08 & -0.11 \\
\hline$>=1.12$ & No & No & & $<68.5$ & & & $<1.5$ & 45.05 & -0.74 & -0.05 \\
\hline$>=1.12$ & No & No & & $<68.5$ & & & $>=1.5$ & 46.92 & -1.38 & -0.1 \\
\hline$>=1.12$ & No & No & & $>=68.5$ & men & & & 48.42 & -1.37 & -0.07 \\
\hline$>=1.12$ & No & No & & $>=68.5$ & women & & & 45.99 & -1.7 & -0.08 \\
\hline$>=1.12$ & Yes & No & & & & $<5.5$ & & 39.2 & -2.52 & -0.14 \\
\hline$>=1.12$ & Yes & No & & & & $>=5.5$ & & 45.83 & -1.04 & -0.05 \\
\hline$>=1.12$ & & Yes & & & & & & 36.75 & -2.94 & -0.17 \\
\hline
\end{tabular}

Note . Control $=$ perceived control. Age $=$ age at death. Religion $=$ Religious activity. Each row corresponds to a leaf in the tree. Correlates as encountered when following a branch from the root of the tree to the respective leaf node are listed on the left part of the table ("Correlates").

Estimated fixed effects for the well-being trajectories are listed on the right side ("Fixed Effects"). 


\section{Figure Caption}

Figure 1. The first two levels of the SEM Tree for terminal decline in well-being comprise social participation and health-related negative life events. Parameter estimates are maximum likelihood estimates with their standard errors. It can be obtained that for people with low social participation (left-hand path), disability emerged as the strongest correlate of differences in latelife well-being trajectories. In contrast, for people with high social participation (right-hand path), it was whether or not they had spent considerable time in the hospital that made a difference for high vs. low and stable vs. declining late-life well-being.

Figure 2. Mean trajectories of terminal decline in well-being corresponding to the groups implied by first-level of the tree (social participation) and the first two levels of the SEM Tree (disability and hospitalization conditioned on social participation). The left-hand panel shows trajectories conditional on low social participation and the right-hand panel shows trajectories conditional on high social participation. Low and high social participation are determined by threshold values at 1.125. It can be obtained that among individuals with low social participation (left-hand Panel), those who had not experienced disability maintained a considerably higher level of well-being all the way until death (by some $0.5 S D, \mu_{I}=43.1$ ) than those who were disabled at some point in their lives $\left(\mu_{I}=36.8\right)$. Among individuals with moderate to high social participation (right-hand Panel), those who had spent considerable time in the hospital reported considerably lower levels of late-life well-being and experienced particularly steep well-being declines relative to those not hospitalized.

Figure 3. The first three levels of the SEM Tree for terminal decline in well-being comprise social participation, health-related negative life events (disability and hospitalization), and perceived control. It can be obtained that the second-level disability branch of the tree was further differentiated at the third level by perceived control, whereas the second-level hospitalization branch of the tree was further differentiated by disability.

Figure 4. Variable Importance for the prediction of group differences in terminal decline in well-being. Variable Importance was derived as proportional drop in likelihood when scrambling correlates in the SEM forest. It can be obtained that the top five variables with the largest influence were - from large to small - disability, hospitalization, social participation, control beliefs, and social goals.

Figure 5. Mean trajectories of terminal decline in well-being corresponding to all leafs in the full tree. Trajectories correspond to row numbers in Table 5 that describe all predictors on the path to each leaf and the average growth curve parameters. It can be obtained that there are 
considerable differences both in well-being at the end of life and in how people reach different end-points, that is, in the shape of terminal decline trajectories. 


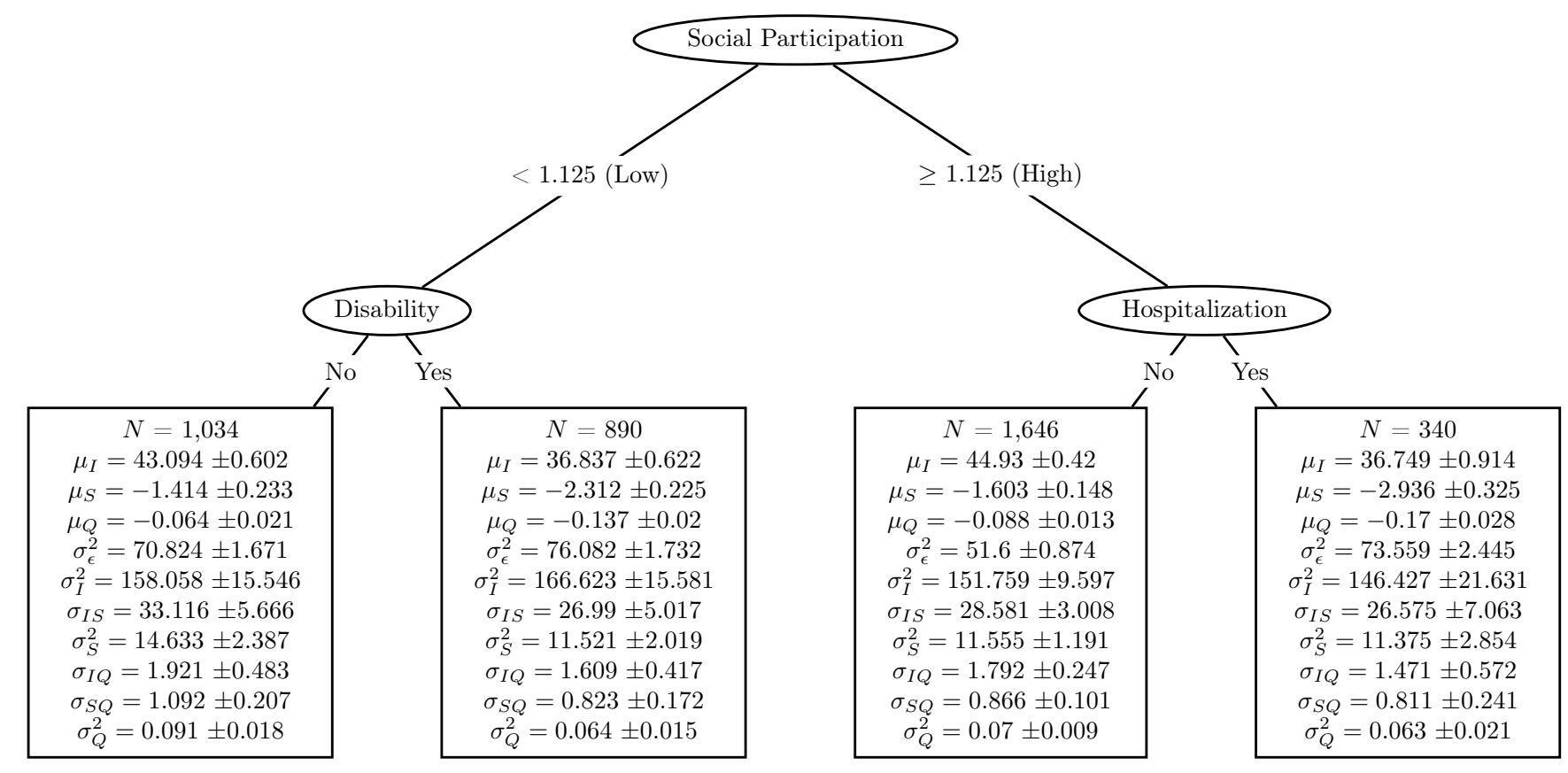


Social Participation

Low

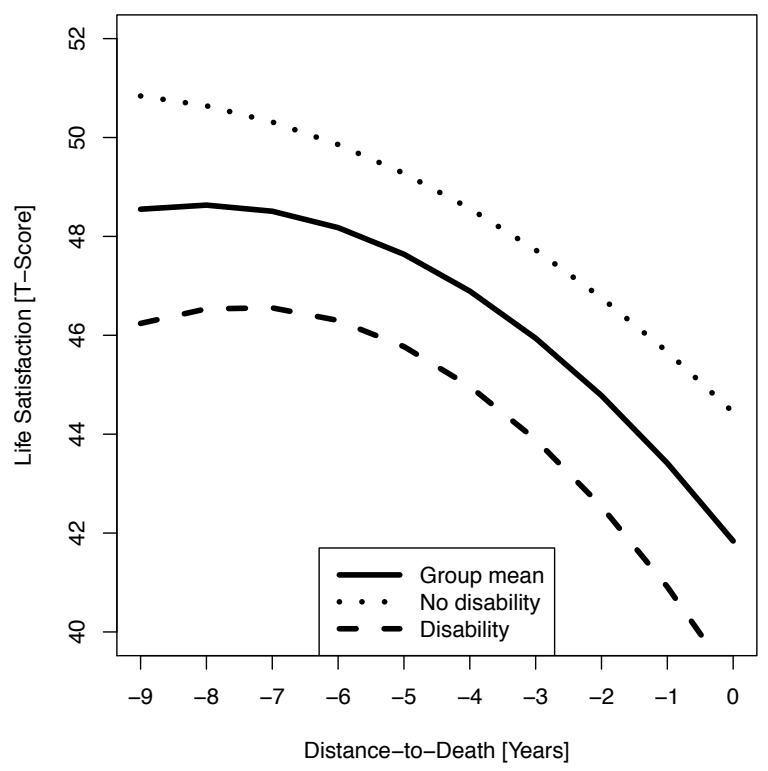

High

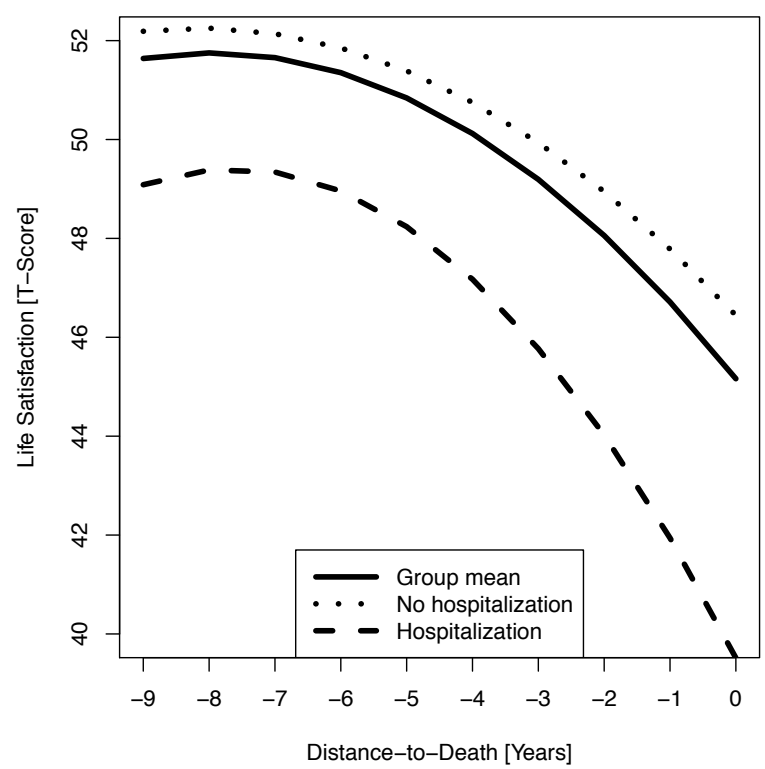




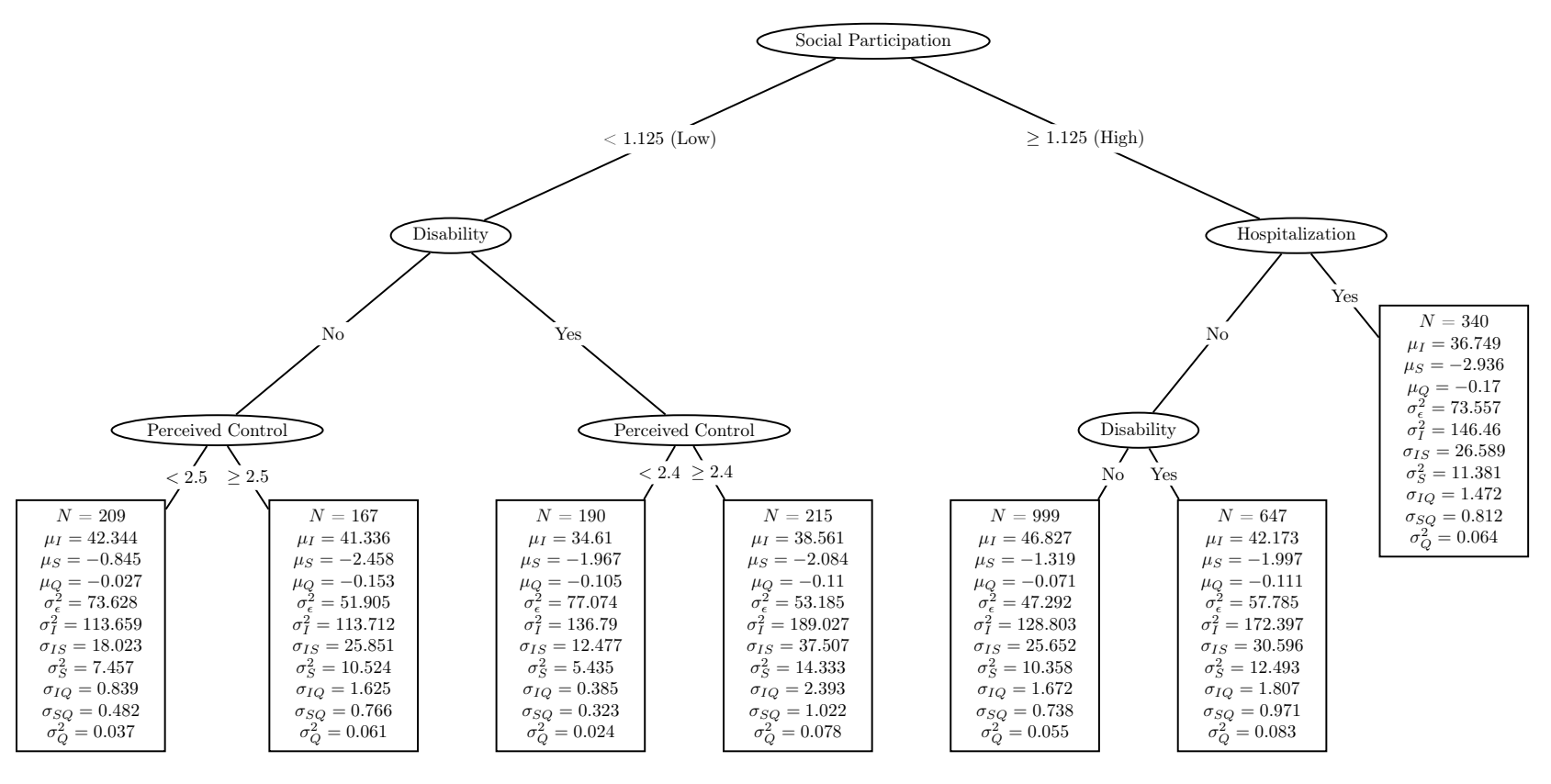




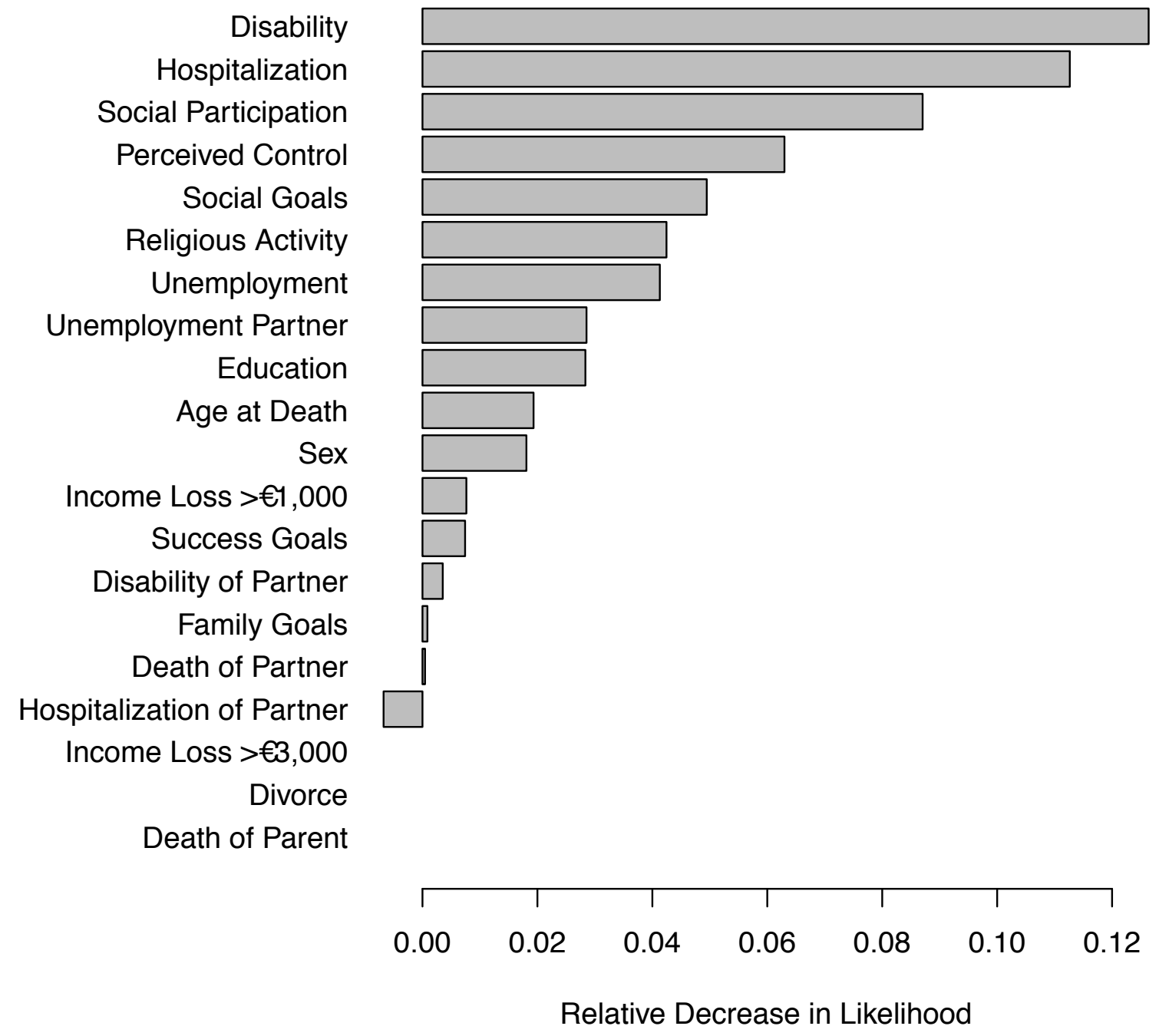




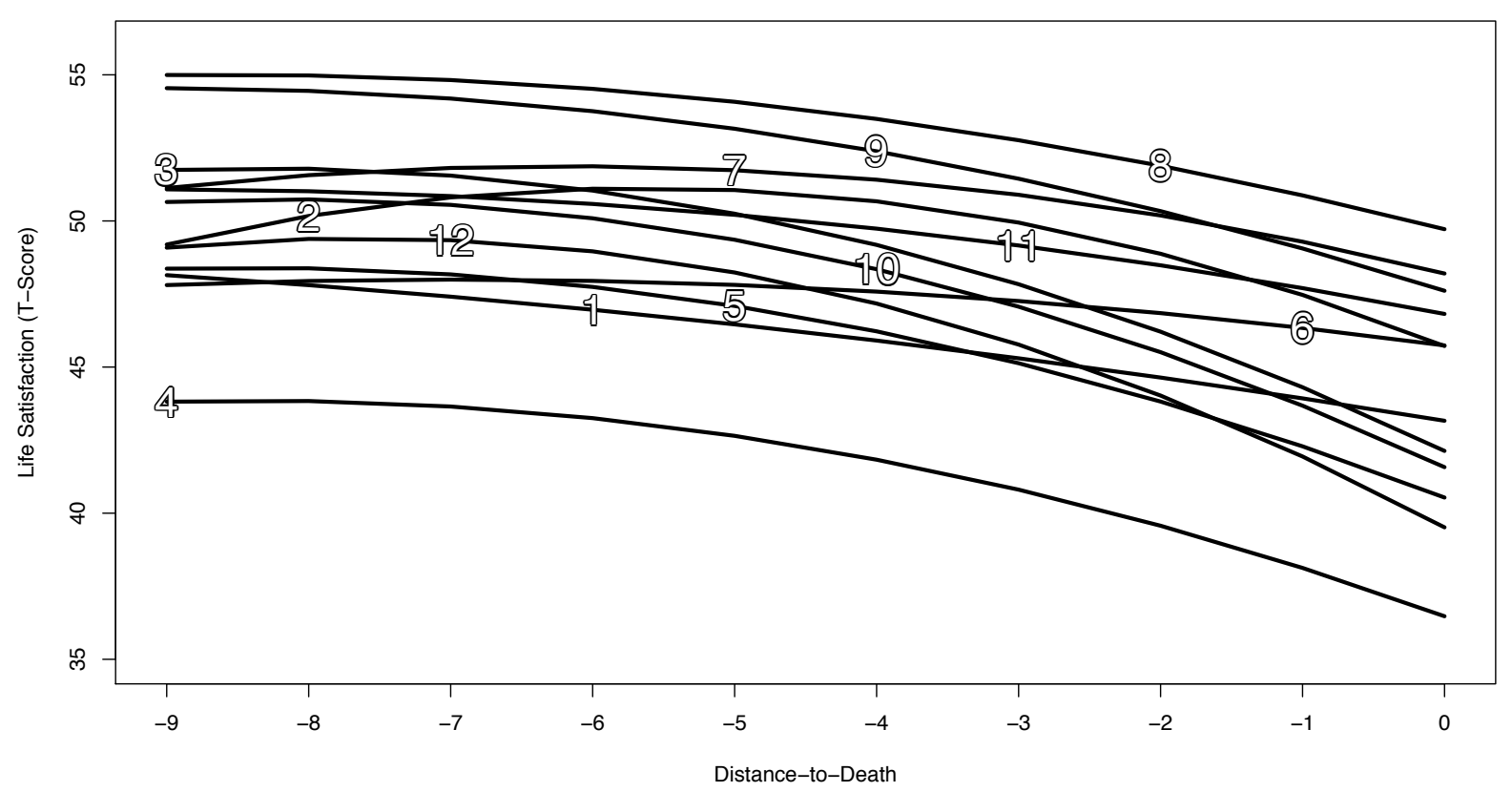

